\title{
Moneda y crédito en una economía en transformación. Santa Fe, Argentina (1858-1883)
}

\section{Currency and Credit in a Changing Economy. Santa Fe, Argentina (1858-1883)}

\author{
Juan Luis Martirén \\ Universidad de Buenos Aires/ \\ Consejo Nacional de Investigaciones Científicas y Técnicas \\ Instituto de Historia Argentina y Americana "Dr. Emilio Ravignani" \\ Buenos Aires, Argentina \\ jmartiren@hotmail.com
}

\begin{abstract}
Resumen
El artículo analiza las trayectorias del circulante monetario y las tasas de interés corriente (de descuento en plaza, bancaria y de crédito notariado) en la provincia de Santa Fe entre 1858 y 1883 . Se trata de un período de crucial importancia, en tanto abarca el ciclo de expansión de la plata amonedada boliviana feble (en sus distintas variantes) y de los primeros bancos de emisión. La evidencia presentada incluye series temporales sobre tasas de interés y cotización de la moneda para el período bajo análisis, confeccionadas sobre la base de publicaciones periódicas de la ciudad de Rosario y libros de contabilidad de empresas de colonización de Santa Fe. Los resultados indican que, pese a los problemas inherentes a su calidad intrínseca, el metálico amonedado boliviano permitió ampliar la oferta de crédito que necesitaba una economía en rápida expansión, al operar como reserva de valor de un nuevo circulante en billete creado por bancos de emisión. Esto redundó además en una trayectoria decreciente del nivel de tasas de interés (con excepción de la coyuntura crítica de 1876) hasta la adopción de la unificación monetaria de inicios de la década de 1880.
\end{abstract}

Palabras clave: moneda; crédito; pesos bolivianos; Santa Fe.

Cómo citar este artículo/ How to cite this article: Martiren, J. L. (2021). Moneda y crédito en una economía en transformación. Santa Fe, Argentina (1858-1883). Revista de Historia Americana y Argentina, 56 (1), pp. 133-172. https://doi.org/10.48162/rev.44.004 


\begin{abstract}
Between the late 1850 s and the early 1880s, currency in Santa Fe province was monopolized by pieces of feeble silver minted in Bolivia. Although the so-called "Bolivian pesos" have been largely studied in the literature, there are key aspects still not fully addressed such as their heterogeneity or effects on the money supply. This paper analyzes the money supply composition and the trajectories of the current interest rates in the province of Santa Fe between 1858 and 1883. The dataset includes time series on interest rates and currency prices built from local newspapers and accounting books of local colonization companies. Preliminary results indicate that, despite its diversified intrinsic quality, the Bolivian coins allowed to expand the supply of credit by operating as a unique reserve of value for convertible banknotes and fiduciary money. This also resulted in a downward trend of interest rates (except during the crisis of 1876) until the adoption of the monetary unification in the early 1880s.
\end{abstract}

Keywords: currency; credit; bolivian pesos; Santa Fe

Recibido: 13/08/2020. Aceptado 7/11/2020

Cualquiera puede comprender la intensidad del mal producido por la falta de una moneda única metálica y propia de la república, ante este Babel de monedas, que no hace sino dificultar el desenvolvimiento del comercio interior y exterior, porque fuera de la variedad del tipo establecido en los diversos presupuestos, la hallamos también en las transacciones comerciales. Tenemos la base del peso fuerte. La del Boliviano. La del papel. Cada comerciante, como cada gobierno, corre tras del oro necesario para pagar las importaciones, y para servir sus deudas, pero ni el oro ni la plata se acuñan en la república, lo cual impone gravámenes que mientras duren han de hacer sufrir al país grandes sacrificios... Diario El Sol, Rosario, 28/02/1877 [Redactor: Gabriel Carrasco] 


\section{Introducción}

Durante la segunda mitad del siglo XIX, la provincia de Santa $\mathrm{Fe}$ experimentó un proceso de gran transformación económica y productiva. Para el cambio de siglo, se había consolidado allí uno de los nichos cerealeros más importantes del país, con cerca de dos millones de hectáreas sembradas (trigo, maíz y lino), y el puerto de Rosario secundaba en importancia al de Buenos Aires. En los planos demográfico, financiero y productivo el crecimiento había alcanzado similares magnitudes.

Determinar cuáles fueron las bases del desarrollo de este particular fenómeno ha sido una constante preocupación en la historiografía académica, con notorios avances al respecto. En efecto, se ha mensurado de forma consistente el ciclo de crecimiento de la economía agraria santafesina, la dinámica de los flujos migratorios, el funcionamiento del negocio de la colonización agrícola, la emergencia de distintos mercados de tierras y de bienes, la evolución financiera y fiscal del erario provincial, entre otros tópicos (Gallo, 1983; Míguez, 1985; Bonaudo y Sonzogni, 1997; Fernández, 1999; Bonaudo, 2006; Djenderedjian, Bearzotti y Martrén, 2010; Frid y Lanciotti, 2013; Garcilazo, 2015; Martirén, 2016; De los Ríos, 2017) ${ }^{1}$.

No obstante, nuestro conocimiento es menor respecto a dos variables de gran importancia en el desarrollo económico de la segunda mitad del siglo XIX: las características de la circulación monetaria y el funcionamiento del crédito, particularmente en las décadas anteriores al gran auge de los años 1880 y 1890.

Es sabido que hasta la unificación monetaria nacional, lograda a partir de un trabajoso proceso entre 1881 y 1883 , la masa de circulante en las provincias estaba monopolizada por monedas extranjeras, con preeminencia de piezas de plata feble (monedas con menor proporción de metal fino en relación a su valor facial) acuñadas en la República de Bolivia, o bien por instrumentos variados nominados en este numerario (Prebisch, 1921; Alvarez, 1929; Platt, 1986; Langer y Conti, 1991; Irigoin y Schmit, 2003; Converso, 2004; Sánchez Román, 2005; Irigoin, 2009; Djenderedjian y Martirén, 2018). Tal como lo ha demostrado un amplio corpus bibliográfico, desde mediados del siglo XIX la moneda adulterada

${ }^{1}$ La lista de trabajos que han analizado la evolución de la economía y del proceso colonizador santafesino durante el siglo XIX es, desde ya, mucho más amplia.

RHAA v. 56 n.1, 2021. ISSN: 0556-5960, ISSNe 2314-1549. CC BY-NC-SA 4.0 
monopolizó la creciente acuñación de plata boliviana (Benavídes, 1972; Platt, 1986; Mitre, 1986; Prado, 2001). Estas piezas se extendieron rápidamente por los mercados regionales que proveían a Bolivia (entre éstos, los de las provincias del interior argentino) donde desplazaron progresivamente del medio circulante a las monedas acuñadas con plata de mayor calidad ${ }^{2}$. La incapacidad de munirse de metal suficiente para cubrir la necesidad de circulante luego de las guerras de la independencia, y sus saldos positivos en el comercio con Bolivia, fueron dos de las principales causas que explican la llegada a las provincias argentinas de estas piezas adulteradas acuñadas en la ceca de Potosí desde 1830.

En Santa Fe la moneda boliviana jugó un rol fundamental en su dinámica económica entre las décadas de 1850 y 1870. La emergencia de la ciudad/puerto de Rosario como centro articulador de los mercados interiores desde mediados de siglo reforzó la necesidad de ampliar el circulante, que pasó a ser cubierto básicamente por piezas febles (Ensinck, 1970; Gallo, 1983; Cortés Conde, 1989; Djenderedjian, Bearzotti y Martirén, 2010). Sumado a ello, los bancos de emisión que surgieron en aquella plaza a mediados de los años 1860 basaron sus emisiones fiduciarias en plata boliviana ${ }^{3}$. Ante la falta de una moneda nacional y los intentos fallidos de los diferentes gobiernos por unificar el sistema monetario, los pesos bolivianos se convirtieron en la principal unidad de cuenta y de cambio en la economía provincial, hasta su definitiva desmonetización en 1883.

La cuestión monetaria en Argentina durante el siglo XIX ha sido ampliamente estudiada por la historiografía económica, en particular para el caso de Buenos Aires, aunque también se han realizado importantes avances respecto a los intentos de la Confederación y de los gobiernos de los años 1860 y 1870 por establecer una moneda propia (Prebisch, 1921; Alvarez, 1929; Amaral, 1988; Cortés Conde, 1989; Irigoin, 2000; Irigoin y Schmit, 2003). Se destacan asimismo excelentes estudios sobre la expansión del crédito y la emergencia de la banca pública y privada durante el siglo XIX, temáticas íntimamente ligadas a la historia de la moneda en

\footnotetext{
${ }^{2}$ Es importante resaltar que el citado libro de Irigoin y Schmit contiene varios estudios de caso sobre el tema, tanto para Potosí como para las provincias argentinas.

${ }^{3}$ Debe advertirse que el primer banco establecido en Rosario, en enero de 1858 (Banco Mauá) realizaba todas sus operaciones en pesos fuertes, al menos hasta 1866. Balances del Banco para 1859 y 1860 en diversos ejemplares del Diario La Confederación, Rosario, 03-04-1859; 07-09-1859; 07-02-1860; 03-07-1860; 02-081860. Sobre los bancos en Rosario, ver también Albaizeta (1987).
}

RHAA v.56 n.1, 2021. ISSN: 0556-5960, ISSNe 2314-1549. CC BY-NC-SA 4.0 
ese época ${ }^{4}$.

Sin embargo, las características de la circulación de la moneda metálica feble y su correspondiente emisión (primero convertible y luego fiduciaria) en Santa Fe presentan aún diversos interrogantes sobre los cuales es necesario avanzar. ¿Qué tipo de monedas componían los pesos bolivianos? ¿Eran sólo las monedas fraccionarias de baja ley las que se identificaban con esta unidad de cuenta? ¿Qué ocurría con las distintas piezas acuñadas con plata fina en Bolivia luego de 1859, que también fueron consideradas como pesos bolivianos? ¿Cómo estaban compuestos los encajes metálicos de los bancos de emisión y en qué piezas se rescataban sus billetes convertibles hasta 1876? ¿Cómo afectó esta moneda al costo del dinero?

Todos estos interrogantes evidencian la complejidad que presenta la circulación de la moneda boliviana y el uso genérico que se le ha dado a esta unidad de cuenta, sin haber indagado aún con mayor detenimiento acerca de la heterogeneidad en la composición de sus piezas y las dificultades derivadas. En tal sentido, el presente trabajo pretende echar luz sobre el asunto a partir del análisis específico de las características del circulante y sus efectos sobre las estructuras del crédito en Santa Fe. Para ello, dividiremos el escrito en dos grandes secciones: por un lado, nos centraremos en el análisis de la moneda, a partir una breve síntesis sobre el origen y las variantes de la piezas febles que monopolizaron la circulación monetaria santafesina entre las décadas de 1850 y 1880 . Por otro, presentaremos evidencia empírica seriada sobre las cotizaciones de esta moneda y su impacto en las tasas de interés corrientes. Nuestra hipótesis principal supone que pese a los problemas inherentes a su calidad intrínseca, las piezas amonedadas bolivianas ofrecieron la posibilidad de ampliar el sistema bancario y, consecuentemente, el medio circulante no metálico, que se mantuvo convertible hasta 1876. Esto permitió, a diferencia de la fallida iniciativa confederal de la década de 1850, la aceptación extendida de los billetes al allanar el camino a la conversión efectiva en metálico. Facilitó a su vez la expansión de distintas formas de crédito a tasas decrecientes (con excepción de la coyuntura crítica de 1876) hasta la

\footnotetext{
${ }^{4}$ Sobre la expansión de la banca en Argentina, ver Regalsky (1999, 2006, 2018); Cortés Conde (1989); Marichal y Gambi (2017). Asimismo, existen muy buenos estudios de caso que han avanzado sobre el funcionamiento de la banca y la circulación de moneda extranjera en el interior, como por ejemplo Albaizeta (1987); Tognetti (1999/2000); Conti (2003); Bragoni (2005); Sánchez Román (2005); Comisso (2012); Moyano (2019).
}

RHAA v. 56 n.1, 2021. ISSN: 0556-5960, ISSNe 2314-1549. CC BY-NC-SA 4.0 
unificación nacional.

\section{Metodología y Fuentes}

En primer lugar, se realizará un análisis histórico y cualitativo sobre los problemas inherentes a los diferentes tipos de moneda boliviana circulante en Santa Fe hasta la adopción de la moneda nacional, que comenzó a correr en la provincia desde noviembre de 1883. Para ello apelaremos a fuentes editas de época (ensayos de especialistas, legislación boliviana y argentina) y a artículos de opinión publicados en diversos periódicos de la prensa rosarina durante el período. Asimismo, presentaremos evidencia seriada sobre cotizaciones de esta moneda y del costo del dinero durante las décadas que sentaron las bases de la gran expansión económica finisecular en la provincia. En cuanto a las cotizaciones, elaboramos series nominales del valor por onza de oro del peso boliviano metálico (1858-1883) y de los billetes del Banco Provincial de Santa Fe nominados en dicha moneda (1877-1883). Para su armado, nos hemos valido de tres fuentes principales: a) los datos sobre mercados de cambios publicados en la prensa periódica de Rosario. Levantamos información de: El Patriota (18581860), El Progreso (1859-1861), La Nueva Era (1861-61), El Diario (18631865), El Rosario (1864-1865), El Ferrocarril (1863-1867), La Época (18711872), El Sol (1877-1878); El Independiente (1878-1883) y La Capital (18671883); b) las cotizaciones de pesos bolivianos (\$B) sobre pesos fuertes $(\$ F)$ presentes en los expedientes de Hacienda del Gobierno Provincial para los años 1866 a 1876; c) datos de cotizaciones de plaza de pesos bolivianos (particularmente en el período 1860-1862 y 1866-1876) tomadas de los libros de contabilidad de la Sociedad de Colonización Suiza de Santa Fe, que corresponden a la colonia San Carlos, en el centro oeste provincial. Los tomos consultados, disponibles en el archivo de Basilea, Suiza (Schweitzerisches Wirtschaftarchiv Basel), fueron: Journale Schweizerische Colonisations-Gesselschaft Santa Fe (SCGSF, en adelante), 1858-1914; Hauptbuch Nro. 1 (1858-1870, Nro. 2 (1860-1865), Nro. 3 (1870-1914); Kollektionen mit Journal-Skripturen für die Kolonie San Carlos (SCGSF), 1858-18735.

\footnotetext{
${ }^{5}$ Agradezco a Mónica Baretta, quien generosamente me brindó información acerca de este repositorio.
}

RHAA v.56 n.1, 2021. ISSN: 0556-5960, ISSNe 2314-1549. CC BY-NC-SA 4.0 
En lo que respecta al estudio del crédito, presentamos series temporales de tasas de interés, con la intención de ofrecer evidencia cuantitativa sobre la evolución del costo del dinero en el período de circulación de moneda extranjera entre 1860 y 1883 . Se trata de tres tipos de series de tasa de interés, tanto bancaria como extrabancaria, a saber: 1) Series de tasas activas (préstamos en cuenta corriente) en bancos públicos (Banco Provincial de Santa Fe y Banco Nacional) y privados (Banco de Londres y Río de la Plata, Banco Comercial, Banco Argentino) con sucursales en Rosario. 2) Series de tasas 'corrientes en plaza', es decir, de descuento de documentos a muy corto plazo, que cubren los años 1858-69. Los datos fueron tomados de los avisos regulares sobre tasas de interés corrientes que publicaban los distintos bancos de Rosario en la prensa provincial (periódicos mencionados en el párrafo anterior). 3) Series de tasas extrabancarias, que se elaboraron a partir de operaciones de crédito notariado entre particulares, con base hipotecaria. Ofreceremos dos series de este tipo: una correspondiente a Rosario (confeccionada con base en 223 operaciones entre 1859 y 1883), y otra, referida a la circunscripción de la ciudad capital de Santa Fe y colonias del centro oeste (que incluyó 202 operaciones entre 1869 y 1883).

\section{La moneda boliviana y su circulación en Santa Fe}

El quiebre revolucionario en Hispanoamérica y los procesos independentistas iniciados en las primeras décadas del siglo XIX generaron profundos efectos monetarios sobre las unidades soberanas emergentes de aquellos procesos (Amaral, 1988; Ludlow y Marichal, 1998; Irigoin, 2009 y 2010; Marichal y Gambi, 2017; Wasserman, 2020). La fragmentación de ese sistema monetario que la Corona española había logrado imponer durante más de dos siglos en sus colonias de ultramar ofrecía nuevos desafíos a las repúblicas en ciernes. En su mayoría sumidas en coyunturas bélicas (internas y/o externas), estas unidades soberanas tuvieron a partir de entonces la posibilidad de ejercer su propio señoreaje de moneda, que efectivamente intentaron poner en práctica para lograr financiar el funcionamiento de sus nuevas instituciones, de su aparato bélico y de sus propias economías (Irigoin, 2010, p. 921-23).

En el Río de la Plata, puntualmente, los vaivenes políticos derivados del proceso de organización estatal postrevolucionario y la reducida capacidad de proveerse de metales, impidieron el establecimiento de una base económica sólida para poder acuñar su propia moneda. Además, la 
atlantización de la economía generó una fuerte divergencia regional, golpeando de lleno en la configuración política de la temprana Confederación Argentina. La desarticulación de los antiguos circuitos mercantiles y la apertura de nuevos mercados para la creciente producción pecuaria del Litoral crearon muy pronto dos realidades distintas que se reflejaron en la evolución del sistema monetario: mientras Buenos Aires logró imponer su propia moneda fiduciaria desde la década de 1820, las restantes provincias del Interior buscaron con escaso éxito el señoreaje en sus respectivos territorios ${ }^{6}$. En suma, la formación de un sistema monetario unificado en el Río de la Plata demoraría más de siete décadas en consolidarse, habiendo coexistido durante ese lapso una multitud de instrumentos basados en metálico amonedado boliviano y en moneda fiduciaria bonaerense.

Entre las razones por las cuales la moneda boliviana se habría expandido con un ritmo acelerado desde mediados del siglo XIX, se encuentra la escasez de numerario metálico y la necesidad de circulante por parte de las provincias del Interior. Ahora bien, ¿por qué esa moneda y no otras piezas de plata u oro que también tenían circulación local, logró cubrir la demanda de metálico con asombrosa versatilidad? En gran parte, porque los volúmenes de llegada fueron crecientes, y pasó a ser el único metal disponible en la cantidad necesaria para cubrir encajes. Esta coyuntura coincidió justamente con la rearticulación de los viejos circuitos mercantiles del interior y con el proceso de bancarización que atravesó Rosario desde los años 1860. Pero, ¿qué incluía la denominación peso boliviano? A continuación haremos una breve síntesis sobre la evolución de estas acuñaciones y los cambios en la legislación boliviana, que determinaron una gran heterogeneidad en el contenido intrínseco de las piezas.

\section{De Santa Cruz a Melgarejo: la acuñación de moneda feble boliviana entre 1829 y 1871}

Luego de la independencia de Bolivia en 1825, la primera ley de monedas del novel gobierno republicano dispuso que las nuevas piezas acuñadas en la Casa de Moneda potosina continuaran teniendo las mismas características (peso, ley, diámetro) que las del último gobierno colonial,

${ }^{6} \mathrm{Si}$ bien hubo otras experiencias de circulación de moneda fiduciaria en algunas provincias (en particular, la de Corrientes), ninguna logró mantenerse hasta la unificación monetaria. Al respecto, ver Cortés Conde (1989).

RHAA v.56 n.1, 2021. ISSN: 0556-5960, ISSNe 2314-1549. CC BY-NC-SA 4.0 
más allá de los cambios lógicos en su estampa o sello. Sin embargo, en octubre de 1829, el presidente Andrés de Santa Cruz permitió, por decreto, un debasement en las piezas amonedadas, mediante el cual se buscó, en principio, mitigar la falta de circulante de moneda menuda (esto es, de ejemplares de 4, 2, 1 y medio real). La ley de esas piezas acuñadas, que hasta ese momento tenía 10 dineros y 20 granos (902,7 milésimos de fino), fue rebajada a 8 dineros, pasando a tener 666,66 milésimos. En otros términos, las nuevas unidades de monedas fraccionarias solo tenían dos tercios del contenido intrínseco de las anteriores, con el mismo valor facial. Esta medida se convertiría en el punto de partida simbólico de los problemas de circulación que aquejarían a las economías del interior argentino hasta la definitiva unificación monetaria de los años 1880.

Como bien ha apuntado Gustavo Prado, el mencionado decreto dejó a discreción del gobierno la cantidad de moneda feble a acuñar, ya que sólo dispuso que el volumen amonedado estuviera determinado por la demanda interna de moneda fraccionaria. Este criterio comenzó a desdibujarse desde la década de 1840, cuando la cantidad de moneda adulterada producida en la ceca de Potosí empezó a crecer de forma significativa, probablemente para cubrir las necesidades fiscales y también para garantizar utilidades en el proceso de amonedación (Prado, 2001; Platt, 1986: 22-23). Entre 1830 y 1859, esta institución acuño algo más de 64 millones de pesos de plata (en monedas de diferente denominación), aunque el 53\% era feble (sobre todo las piezas de 4 reales, denominadas popularmente como 'cuatros', que fueron las que pasaron a circular en gran cantidad en las provincias del Interior). El ciclo de producción de monedas se intensificó aún más en la década de 1850, cuando este guarismo alcanzó el $89 \%$ (durante dicho decenio, se sellaron 21.250 .214 pesos de plata feble, es decir, el $33 \%$ del total de la plata acuñada desde la promulgación del decreto de octubre de $1829)^{7}$.

Este notable incremento de piezas febles había comenzado a generar efectos negativos en la economía boliviana, sobre todo porque la producción de monedas de plata fuerte había disminuido drásticamente. Si bien hubo intentos fallidos por corregir esta situación a fines de la década de 1840 (en particular por presión de comerciantes peruanos), recién en 1859 se decidió hacer un cambio en la legislación monetaria, por iniciativa el

${ }^{7}$ Cálculos elaborados con base en la tabla de acuñaciones provista por Vargas
(1866, p. 25). Datos de acuñaciones por anuales entre 1830 y 1871 en Anexo 1. RHAA v. 56 n.1, 2021. ISSN: 0556-5960, ISSNe 2314-1549. CC BY-NC-SA 4.0 
ministro Tomás Frías. Mediante decreto, se dispuso la creación de una nueva moneda legal, que respetaría el contenido intrínseco de los pesos fuertes (esto es, 10 dineros y 20 granos, o 900 milésimos de fino), aunque las nuevas piezas tendrían una reducción en su peso ${ }^{8}$. Lo que se buscaba con esta ley era recuperar la acuñación de pesos fuertes, más allá de que ya no tuvieran el mismo tamaño que los acuñados en las décadas anteriores. En términos de un autor de la época, "se aumentó el fino de la moneda, pero se disminuyó en proporción el peso de cada pieza monetaria, quedando así fuerte en cuanto a la combinación metálica, i feble en cuanto al peso [sic]" (Sotomayor Valdés, 1874, p. 114).

En junio de 1863 se sancionó una nueva ley de monedas, que abandonó el viejo sistema octal (es decir, del peso de ocho reales), y dispuso la aplicación del sistema centesimal. A solo cuatro años de creada la nueva moneda, y luego de frenar temporalmente la acuñación de moneda feble, las autoridades consideraron que era necesario adaptar el sello al sistema decimal, que estaba comenzando a utilizarse en varios países de América9. Las nuevas monedas serían acuñadas con ley de 900 milésimos (o 9 décimos), teniendo las de mayor denominación un peso de 500 granos ponderales, igualándolas así con las que se acuñaban en Perú o Chile. Estas monedas se ubicaban en un punto intermedio entre las piezas fuertes acuñadas hasta 1859 (542 granos) y los Pesos Frías de 1859-63, que pesaban 400 granos. La ley fijaba asimismo un nuevo sello y su conversión con la onza de oro pasaría a ser de 17,5 a $1^{10}$.

La nueva ley de monedas de 1863 venía a profundizar los esfuerzos por evitar la adulteración de la moneda en la ceca de Potosí, y a la vez a adaptarse a las características que el ensayo de monedas tenía en otros países. Sin embargo, durante el gobierno del general Mariano Melgarejo (1864-1871), las disposiciones de esta ley no fueron del todo cumplidas. Si bien continuó la acuñación de monedas bajo el sistema centesimal e incorporó maquinaria más moderna para los talleres de la Casa de Moneda,

\footnotetext{
${ }^{8}$ Lo que hacía la nueva ley era mantener el contenido fino de plata en 900 milésimos (equivalente al de la plata fuerte), pero rebajaba el peso de las piezas a 400 granos ponderales. Es de destacar que los pesos fuertes españoles o bien los acuñados hasta ese momento en la república boliviana debían tener 542 granos.

`Un análisis sobre los alcances y las resistencias a esta ley en Platt, 2010.

10Una explicación detallada sobre los cambios legislativos en relación a la moneda boliviana y las dificultades en la transición del sistema octal al centesimal en Platt (2010).
}

RHAA v.56 n.1, 2021. ISSN: 0556-5960, ISSNe 2314-1549. CC BY-NC-SA 4.0 
también volvieron a acuñar monedas de 400 granos y ley de ocho dineros (es decir, con 667 milésimos de fino). Melgarejo no sólo rebajó el contenido intrínseco y el tamaño de las piezas, sino que también cambió su cuño (incluyendo su busto, junto al de su ministro de Gobierno). Estas nuevas monedas (también conocidas como 'melgarejos'), fueron resistidas en Bolivia, por lo que el gobierno se vio obligado a suspender su acuñación y rebajar legalmente su valor a 6 reales por peso. Con todo, se diseminaron rápidamente en los mercados de las provincias argentinas, y aumentaron aún más las dificultades derivadas de la heterogeneidad del metálico amonedado boliviano circulante ${ }^{11}$.

El derrocamiento de Melgarejo en 1871, la baja de la cotización de la plata en el mercado internacional y posteriormente la crisis económica de 1873 determinarían el fin del ciclo de grandes emisiones de moneda feble en Bolivia. Sin embargo, los problemas de los distintos espacios económicos que la habían absorbido recién estaban comenzando. Las piezas de plata que quedaron en circulación acuñadas en la ceca de Potosí (y en mucha menor medida en la de La Paz, que funcionó entre 1853 y 1859) incluían un abanico variado, a saber:

-Pesos de ocho reales, con ley de 10 dineros y 20 granos (903 milésimos) y 542 granos de peso (se trataba de los viejos pesos fuertes españoles o las piezas acuñadas entre 1826 y 1859)

-Monedas menudas febles (de 4, 2, 1, medio real y un cuartillo) de 8 dineros (667 milésimos), acuñadas entre 1830 y 1859 . En este grupo se incluían los populares cuatros (piezas de 4 reales o medio peso), que invadieron los mercados del interior argentino.

-Pesos de ocho y cuatro reales, con ley de 10 dineros y 20 granos (900 milésimos de fino) y un peso 400 y 200 granos, que se acuñaron entre 1859 y 1863.

-Pesos del sistema decimal, con ley de 10 dineros y 20 granos (900 milésimos de fino) y un peso 500 granos, que se acuñó entre 1863 y 1871.

\footnotetext{
${ }^{11}$ Esta cuestión ha captado la preocupación de varios investigadores, tanto del campo de la historia económica, como en la numismática. Al respecto, ver: Segreti (1975); Conti (2003); Converso (2004); Djenderedjian y Martirén (2018); Moyano (2019).
}

RHAA v. 56 n.1, 2021. ISSN: 0556-5960, ISSNe 2314-1549. CC BY-NC-SA 4.0 
-Moneda fraccionaria del sistema decimal, con ley de 10 dineros y 20 granos (medio peso, tomín, décimo y medio real), acuñada entre 1863 y 1871.

-Piezas de ocho y cuatro reales llamados Melgarejos, con ley de 8 dineros (667 milésimos), pesando 400 granos los de ocho reales y 200 los de cuatro. Acuñadas al menos entre 1865 y 1866. (Imagen $n^{\circ} 1$ ).

Imagen $\mathrm{n}^{\circ}$ 1: Pesos bolivianos febles y fuertes de las décadas en 1830 a 1870

\begin{tabular}{|c|c|c|}
\hline PERÍODO & TIPO & IMAGEN \\
\hline $1826-1859$ & $\begin{array}{c}\text { Moneda de } 8 \text { reales } \\
\text { (peso fuerte) } \\
\text { Plata fina: } 903- \\
542 \text { granos }\end{array}$ & \\
\hline $1830-1859$ & $\begin{array}{c}\text { Moneda de } 4 \text { reales } \\
\text { (cuatro feble) } \\
\frac{\text { Feble: } 667-271}{\text { granos }}\end{array}$ & \\
\hline $1859-1863$ & $\begin{array}{c}\text { Moneda de } 8 \text { reales } \\
\text { (Pesos Frías) } \\
\text { Plata Fina: } 900 \\
\frac{\text { Peso feble: }}{\text { granos }} 400\end{array}$ & \\
\hline $1863-1871$ & $\begin{array}{l}\text { Moneda de } 100 \\
\text { centésimos (1 } \\
\text { peso, sistema } \\
\text { decimal) } \\
\text { Plata fina: } 900- \\
500 \text { granos }\end{array}$ & \\
\hline $1865-1866$ & $\begin{array}{c}\text { Moneda de } 8 \text { reales } \\
\text { (Pesos } \\
\text { Melgarejos) } \\
\text { Feble: } 667-400 \\
\text { granos }\end{array}$ & \\
\hline
\end{tabular}

Fuente: Elaboración propia a partir de información provista por el Museo Virtual de Monedas y Billetes del Banco Central de Bolivia. Imágenes recuperadas de: https://www.bcb.gob.bo/?q=museo-virtual 
En suma, este repaso de la variedad de las acuñaciones bolivianas y sus diferentes valores intrínsecos hasta la década de 1870 permite comprender las dificultades que trajo aparejadas la denominación 'peso boliviano' como moneda de cuenta y de cambio en el Interior argentino. Esta complejidad no fue del todo advertida en los estudios que han analizado la moneda, identificando como 'pesos bolivianos' a un amplio espectro de acuñaciones potosinas que tuvieron, sin duda, cotizaciones disímiles. A continuación veremos su expansión en los mercados de las provincias desde la década de 1840, su consolidación como moneda corriente en Santa $\mathrm{Fe}$ y el surgimiento de la moneda convertible (y luego fiduciaria) nominada a ésta.

\section{La llegada de la moneda feble a Santa Fe y los primeros bancos de emisión}

La formación de la Confederación Argentina luego de la batalla de Caseros, en 1852, no sólo tuvo un impacto político por haber unido a las distintas soberanías provinciales del Litoral y del Interior, sino también porque promovió la emergencia de un nuevo enclave comercial y financiero con sede en la ciudad de Rosario, que pasaría a articular los viejos circuitos mercantiles, en gran parte ligados al comercio con Bolivia y Chile (Langer y Conti, 1991; Converso, 2004; Bragoni, 2005; Dalla Corte, 2009; De los Ríos, 2017). La instalación de una nueva aduana en el puerto de aquella urbe y el desempeño de la economía pecuaria del Litoral, que ya venía en franco crecimiento desde los tempranos años 1840, fueron factores determinantes en el desarrollo de instituciones y corporaciones en aquella plaza ${ }^{12}$.

Si bien los saldos exportables desde la aduana rosarina generaban ingresos en oro, las operaciones de la economía doméstica (e incluso la moneda corriente en las operaciones del estado provincial) se realizaban a plata 'fuerte' o patacones (una unidad de cuenta ficticia, que podía incluir tanto los viejos pesos españoles como a las denominadas "monedas patrias" y a las piezas de 12 dineros y 20 granos acuñadas luego de la independencia boliviana). Con el auge de la producción de piezas febles desde los años 1850, pero sobre todo durante el impulso comercial de Rosario durante el decenio siguiente, la composición del medio circulante en territorio provincial

\footnotetext{
${ }^{12} \mathrm{Al}$ respecto, cabe destacar que en enero de ese año se instaló la primera sucursal del Banco Mauá (de capitales brasileños), y nueve meses después, el Casino Mercantil. Carrasco (1864: p. 375-78).
}

RHAA v. 56 n.1, 2021. ISSN: 0556-5960, ISSNe 2314-1549. CC BY-NC-SA 4.0 
inició un proceso de transformación. Los pesos fuertes comenzaron a perder terreno ante una nueva unidad de cuenta -el 'peso boliviano'-cuya denominación englobaba, hasta entones, a las monedas devaluadas de 8 dineros y 667 milésimos de fino acuñadas desde 1830, con una equivalencia teórica de 21 unidades por onza de oro. Estas nuevas piezas pasaron a ocupar un lugar de indiscutida preeminencia ${ }^{13}$.

Ello coincidió con la expansión de la economía provincial (y la consiguiente necesidad de circulante), con la instalación de algunos bancos de emisión en Rosario y también con el impulso económico y mercantil que generó la construcción del Ferrocarril Central Argentino. Si bien la primera institución bancaria instalada en la provincia (el Banco Mauá y Cía.) databa de enero de 1858, algunas dificultades financieras y desentendimientos con las autoridades de la Confederación hicieron que el banco redujera sus operaciones $^{14}$. A lo largo de los años 1860 llegarían nuevas entidades que dinamizarían el medio circulante y el mercado de crédito, luego de que en 1863 se autorizara por ley el establecimiento de bancos de emisión (Ensinck, 1970, pp. 255-261; Albaizeta, 1987). Traerían aparejado, además, un cambio fundamental: harían gran parte de sus emisiones convertibles en pesos bolivianos. En 1864 se fundó el Banco Casado, que en 1866 sería adquirido por Rosario del Banco de Londres y Río de la Plata (que ya tenía una sucursal en Buenos Aires y Montevideo), y luego lo acompañaron el Banco del Rosario (llamado Banco Argentino desde agosto de 1866) y el Banco Comercial ${ }^{15}$.

\footnotetext{
${ }^{13}$ Es interesante traer a colación la opinión de Carlos Beck (uno de los principales protagonistas de los orígenes de la colonización en Santa Fe), acerca de la circulación de pesos bolivianos. Para mediados de la década de 1860, Beck suponía que con la ley monetaria de Bolivia de 1863, las piezas febles irían a desaparecer: "En Santa Fe y en la mayoría de las provincias, la moneda que circula es el peso boliviano, dividido en ocho reales. Todavía es una moneda abusiva cuyo valor, en relación con la onza de oro, varía diariamente entre 20 y 22 pesos aproximadamente, y que afortunadamente tiende a desaparecer, ya que se ha sacado del mercado en la propia Bolivia, que introdujo un nuevo sistema monetario exactamente similar al de Chile." En Beck (1865, p. 16). Original en francés, traducción del autor.

${ }^{14}$ El Banco Mauá tuvo una importancia fundamental en el desarrollo financiero y bancario de Rosario entre fines de los años 1850 y la primera mitad de la década de 1860. Sin embargo, sus emisiones fueron realizadas sobre pesos fuertes, lo que no generó una expansión de su circulante hacia el comercio minorista.

${ }^{15} \mathrm{El}$ Banco Comercial, propiedad de Mariano Cabal (influyente comerciante y
}

RHAA v.56 n.1, 2021. ISSN: 0556-5960, ISSNe 2314-1549. CC BY-NC-SA 4.0 
Estas instituciones, que debían contar con encajes metálicos correspondientes al $30 \%$ de sus billetes en circulación, tuvieron efectos positivos -como veremos en el último apartado-sobre el limitado mercado de crédito que operaba en aquella plaza. Al ser autorizados por el gobierno provincial a emitir billetes nominados en 'pesos bolivianos', los bancos lograron saltear las dificultades y el riesgo que suponía encajarse en plata fuerte, mucho más escasa. Así la circulación de los nuevos billetes y su efecto multiplicador favorecieron la consolidación de los pesos bolivianos como principal moneda de cuenta ${ }^{16}$.

Los gráficos siguientes (Gráfico $n^{\circ} 1$ y 2 ) ilustran la evolución mensual de la existencia en caja en metálico y de los billetes en circulación en los dos principales bancos de emisión de Rosario de la segunda mitad de la década de 1860 y la primera de la del 1870. Pese a las lagunas en la información disponible, puede notarse claramente la mencionada preeminencia del peso boliviano, tanto en la liquidez de metálico como en la emisión de billetes convertibles. Si bien estos gráficos no incluyen el rubro "Documentos descontados", es importante apuntar que los descuentos de ambos bancos en moneda boliviana ocupaban el 67 y el $71 \%$ del total durante el período comprendido en ambos gráficos. En suma, pese a que no contamos con datos concretos sobre la cantidad y el tipo de circulante metálico en la provincia, a partir de esta evidencia indirecta podemos obtener una perspectiva aproximada tanto de la composición de la masa circulante, como de los ciclos de contracción y expansión de la emisión. Esto es importante al observar los movimientos del Banco Argentino, cuyos mayores volúmenes en existencia y circulación (en especial en pesos fuertes) en 1867 reflejan el auge económico y financiero que atravesó la provincia en esos años ${ }^{17}$.

gobernador de la provincia) había sido autorizado por ley provincial el 25 de junio de 1867. Sin embargo, su existencia fue corta, ya que entró en liquidación el 23 de septiembre 1868, con la crisis económica que Cabal debió enfrentar luego de una fuerte corrida contra sus billetes. Ver La Capital, Rosario, 23-09-1868.

${ }^{16}$ Ley del 11-07-1866: Autoriza al BL\&RP a emitir en moneda boliviana, en Provincia de Santa Fe, 1889: Tomo V, p. 134. Por su parte, el Banco del Rosario ya había sido autorizado en sus estatutos de fundación a emitir en bolivianos o fuertes. Ver Provincia de Santa Fe (1889, Tomo 4, p. 359).

${ }^{17} \mathrm{Es}$ de destacar que este banco redujo significativamente sus operaciones desde 1869, y comenzó su proceso de liquidación en 1874. Sobre el impacto de la Guerra

RHAA v. 56 n.1, 2021. ISSN: 0556-5960, ISSNe 2314-1549. CC BY-NC-SA 4.0 
Gráficos $\mathrm{n}^{\circ} 1$ y 2: Evolución del metálico en caja y de los billetes emitidos en circulación del Banco de Londres y Río de la Plata y del Banco Argentino de Rosario (1866-1872)
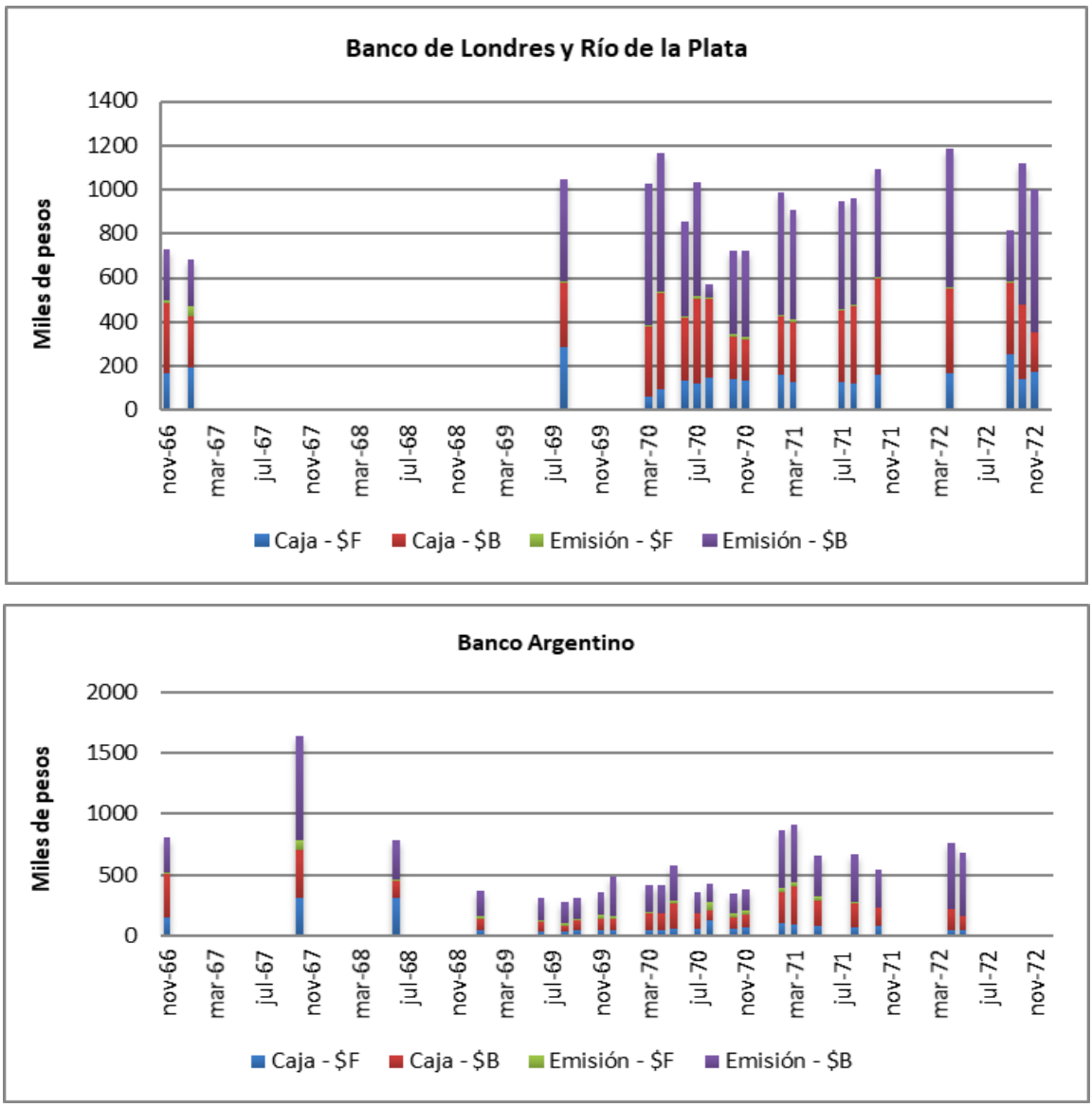

Fuente: Elaboración propia a partir de datos de balances publicados mensualmente por dichas instituciones bancarias en los diarios de la ciudad de Rosario. Los balances del Banco Argentino, se tomaron de: El Ferrocarril, 12-12-1866 y 10-101867; La Capital, 15-09-1868, 31-07-1869, 03-10-1869, 25-11-1869; La Reforma, 3012-1869, 14-01-1870, 07-05-1870, 28-05-1870, 20-06-1870, 06-09-1870; La Época,

del Paraguay en la economía santafesina, ver Djenderedjian, Bearzotti y Martirén (2010); Martirén (2012). 
03-10-1870, 17-11-1870, 29-12-1870, 18-07-1871, 11-05-1872, 10-06-1872, 08-111872; La Opinión Nacional, 09-05-1871. Los correspondientes al BL\&RP, se consultaron en: El Ferrocarril, 07-12-1866, 09-02-1867; La Capital, 02-10-1869; La Reforma, 22-05-1870, La Opinión Nacional, 10-08-1870, 04-04-1871, 09-05-1871, 03-09-1871, 14-10-1871; La Época, 03-10-1870, 17-11-1870, 29-12-1870, 11-051872; El Mercurio, 03-12-1872. Nota: (\$F) pesos fuertes; (\$B) pesos bolivianos.

De todas maneras, también es necesario subrayar que el mayor stock de moneda fuerte que registran ambas entidades en 1868 o 1869 obedeció a distintas disposiciones estatales. Se trata de los primeros ajustes a la liberalización de la emisión de 1865, y buscaban probablemente evitar grandes aumentos en la circulación de piezas de menor calidad, como los cuatros de la década de 1850 o los melgarejos de 1865-1866. El gran crecimiento del comercio y de los precios agrarios por la demanda de los ejércitos en la Guerra de la Triple Alianza contra el Paraguay redundó en un fuerte aumento del circulante metálico, por lo que las autoridades estatales decidieron fijarle valor con respecto al peso fuerte y, a la vez, obligar a los bancos a pagar el rescate de sus billetes sobre la base del tipo fijado para la conversión ${ }^{18}$. Desde entonces, si bien con estrategias diferentes, ambas instituciones comenzaron a reemplazar progresivamente el circulante metálico (tanto en $\$ \mathrm{~F}$ como en \$B) por emisión en \$B.

\section{La emisión los años 1870: ¿el monopolio de la moneda fiat?}

El escenario anteriormente reseñado fue desdibujándose en la década de 1870, cuando la circulación de este numerario comenzó a ser vista como un problema grave. En efecto, si el crecimiento de las instituciones bancarias y del medio circulante habían jugado un rol esencial en la expansión dela economía provincial hasta ese momento, también habían dejado algunas contrapartidas. Una de ellas fue la diversificación de los instrumentos monetarios, impulsada por la llegada de nuevas piezas febles (los melgarejos, desde 1865) y también por el surgimiento de billetes y vales de

\footnotetext{
${ }^{18}$ Mediante una ley sancionada el 30 de julio de 1868, dispuso que el peso fuerte equivalía a 10,5 reales bolivianos (esto es, cerca de un $30 \%$ menos), o bien con una equivalencia teórica de 21 pesos bolivianos por onza de oro. El estado provincial fijaba así, por ley, el valor que por entonces tenía en plaza la plata amonedada boliviana. Asimismo, en su artículo segundo, la ley obligaba a los bancos de emisión a pagar sus billetes en moneda fuerte, siguiendo esa conversión. De ahí la necesidad de contar con encajes altos para evitar eventuales corridas.
}

RHAA v. 56 n.1, 2021. ISSN: 0556-5960, ISSNe 2314-1549. CC BY-NC-SA 4.0 
casas comerciales -e incluso de bancos de otras provincias- que pasaron a operar como moneda en papel convertible. Sobre este punto, cabe citar la opinión de Guillermo Wilcken (Inspector de Colonias de la provincia) quien, en su detallado informe sobre la actividad agrícola en la campaña durante el año 1872, resumió claramente el inconveniente que causaba la diversidad que caracterizaba al medio circulante:

Véase lo que pasa con la moneda [en Santa Fe], en que unos calculan por pesos fuertes y otros por pesos bolivianos, mientras que hablando solo de pesos, sin el calificativo, surgen y originan errores, equivocaciones y disputas...

Las transacciones sobre tierras y concesiones se realizan generalmente a boliviano; pero también se hacen por el tipo del peso fuerte. Una misma cosa, un mismo objeto, se vende hoy a fuertes, mañana a boliviano.

Pero la cosa no queda en esto; que para colmo de confusiones en que el transeúnte especialmente se ve envuelto, la moneda más familiar consiste en una variedad infinita de billetes de bancos particulares de Santa Fe, Entre Ríos y Córdoba, cuya emisión simultáneamente en ambos tipos de fuerte y boliviano, no hace sino aglomerar inconvenientes agregando su parte a las causas generales de la confusión... (Wilcken, 1873: p. 276)

La "variedad infinita de billetes" a la que Wilcken aludía con preocupación fue resultado del auge económico generado por la guerra en Paraguay y por el creciente desarrollo que en esos años logró la economía agraria provincial a partir de la expansión de los núcleos primigenios de colonización agrícola y de la creación de nuevas colonias linderas a las vías del Ferrocarril Central Argentino. La competencia entre los bancos rosarinos y sus emisiones expandió el crédito y satisfizo la demanda de circulante, que aumentó sustancialmente al calor del auge del mercado inmobiliario, de un incremento creciente en el valor de la tierra y, por ende, en el volumen y monto de las transacciones comerciales. Habida cuenta de este contexto, la utilización de moneda en papel de mayor denominación se tornó una herramienta útil para evitar grandes y costosos traslados de metálico entre particulares (Imagen $\mathrm{n}^{\circ} 2$ ). 
Imagen $\mathbf{n}^{\circ}$ 2: Billete nominado en Pesos Bolivianos del empresario Fermín Laprade

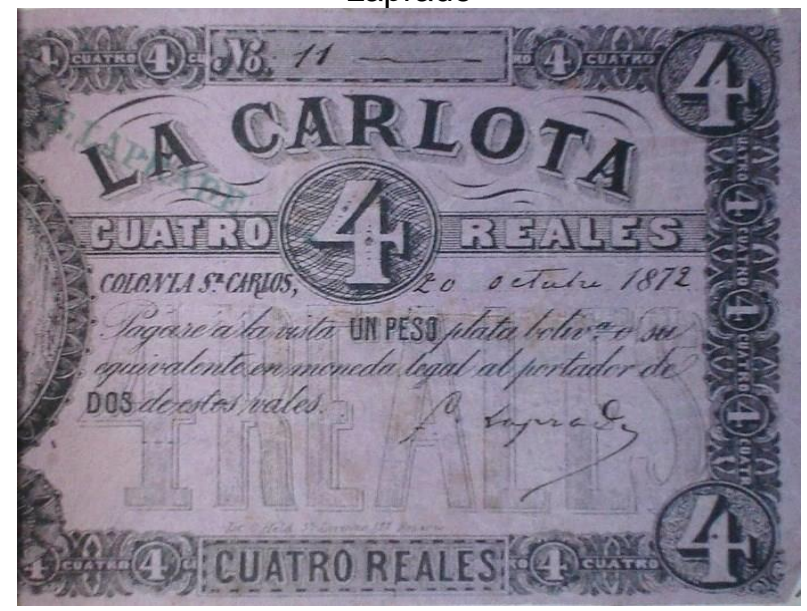

Fuente: Archivo General de la Provincia de Santa FE (AGPSF), Fondo Gobierno, Tomo 37, 1872, f. 1368

En ese escenario, la creación del Banco Provincial de Santa Fe (en adelante BPSF), en mayo de 1874, imprimiría un nuevo ritmo a la dinámica de circulación de moneda fiduciaria. Si bien se trató de una empresa de capitales mixtos (se creó por ley provincial, con capital de 2 millones de pesos fuertes dividido en 20.000 acciones, la mitad de las cuales serían suscriptas por el estado provincial a través de préstamos internacionales) (Provincia de Santa Fe, 1890: Tomo VIII, pp. 232-239), su instalación obedecía a la sentida necesidad de establecer un banco de emisión con participación estatal para promover el ahorro e impulsar el crédito. En octubre de ese mismo año la provincia permitió al Banco la emisión de billetes en moneda boliviana (Agote, 1881, p. 435). Al momento de iniciar sus operaciones, funcionaban en la provincia otros dos bancos de emisión: el de Londres y Río de la Plata, que era el más importante, y una sucursal del Banco Nacional, ubicada en Rosario, aunque no jugaba un rol destacado en el sistema financiero local ${ }^{19}$. La flamante institución provincial

\footnotetext{
19"Parece que este establecimiento quisiera volver de la inacción en que hace tiempo se encontraba. Sus operaciones eran tan limitadas que podría decirse que no hacía ni para los gastos de la casa. La crisis porque atravesó Buenos Aires contribuyó en gran parte a la paralización completa del Banco Nacional. Era consiguiente que la
}

RHAA v. 56 n.1, 2021. ISSN: 0556-5960, ISSNe 2314-1549. CC BY-NC-SA 4.0 
traería aparejadas grandes transformaciones, no tanto por sus mayores dimensiones en cuanto al capital (y su consiguiente impacto en el mercado de crédito), sino porque habría de generar efectos significativos en el medio circulante santafesino entre 1876 y $1883^{20}$.

Como se señaló anteriormente, durante la década de 1870 la moneda boliviana (o bien la falta de un patrón monetario unificado) pasó a ser una preocupación, tanto en Santa Fe como en el resto de las provincias. La crisis financiera iniciada en Europa en 1873, el progresivo cierre de los mercados de crédito internacionales y la baja del precio de la plata a nivel mundial generaron importantes trastornos en la economía argentina, cuyos efectos se sintieron con fuerza en $1876^{21}$. En el plano nacional, se buscó con escaso éxito la imposición de una nueva moneda, mediante la sanción de la Ley 733 de Moneda Nacional en septiembre de 1875 y el dictado de sucesivos decretos que fijaban valores a las piezas extranjeras que circulaban en el país 22 . Sin embargo, la falta de metálico y los efectos de la crisis impidieron ponerla en práctica, de modo que, al decir de Alvarez, "sólo llegó a ser otra moneda de cambio superpuesta a las anteriores" (1929, p.

sucursal del Rosario se limitara también y subiera el interés del dinero al $18 \%$ mientras los demás lo daban a una tasa mucho menor". El Comercio, Rosario, 1609-1875. Sobre el tema, ver Cortés Conde (1989); Regalsky (1999); Moyano (2019). ${ }^{20}$ Desde su creación hasta 1883, el BPSF cambió 6 veces sus estatutos. Según Agote, pese a su capital mixto, los distintos gobiernos provinciales abusaron de su participación accionaria para generar reformas que, en muchos casos, violaban incluso leyes nacionales, como la emisión de moneda fiduciaria boliviana. Ver Agote (1884, p. 274).

${ }^{21}$ Sobre el impacto de esta crisis en la economía nacional, ver Gerchunoff, Rossi y Rocchi (2008).

${ }^{22}$ Esta norma creaba una nueva moneda de oro nacional, de base decimal, que se llamaría 'peso fuerte'. Se disponía, además, que el Estado Nacional fijase el valor de las monedas corrientes en el país, a partir de su contenido intrínseco de metal fino. Se trataba de una iniciativa ambiciosa en tanto buscaba solucionar el desorden monetario derivado de la variopinta composición del medio circulante en el Interior, sujeto por tanto a altos costos de intermediación. En virtud de esta ley, el Poder Ejecutivo Nacional dictó sucesivos decretos (6 de julio y 18 de septiembre de 1876; 10 de marzo de 1877 y del 14 de enero 1879), los cuales fueron fijando los valores relativos a las monedas extranjeras. Empero, fueron discutidas en las diferentes provincias, ya que estas normas no incluían a las piezas febles bolivianas, es decir, ni a los cuatros ni a los Melgarejos, que circulaban en cantidad. En suma, todos los intentos de las autoridades nacionales por eliminar la circulación de la boliviana fueron estériles durante el segundo lustro de la década de 1870.

RHAA v.56 n.1, 2021. ISSN: 0556-5960, ISSNe 2314-1549. CC BY-NC-SA 4.0 
114). Valen, como ejemplo, las palabras de Gabriel Carrasco, editor del diario rosarino El Sol, cuando afirmaba:

El boliviano es malo -convenido-, pero con qué se reemplaza esa mala moneda? Esa es la cuestión, pretender con leyes [Ley de Monedas Nacional de 1875] desterrar una costumbre que se funda en la necesidad, es acometer un imposible. El boliviano circulará forzosamente hasta el día en que las casas de moneda nos den una mejor. Obligando a los bancos a emitir a fuerte, no se conseguirá el objeto que se han propuesto, pues, si bien no circularán los billetes, circulará el efectivo ${ }^{23}$.

En esencia, las palabras de Carrasco apuntaban al primer decreto de fijación del valor de las piezas extranjeras luego de la sanción de la ley de monedas de 1875 y a la posterior ley del 24 de octubre de 1876 (de reorganización del Banco Nacional) que prohibía a los bancos de emisión del Interior tener circulante fiduciario en moneda extranjera. El problema de ambas leyes radicó en que sus disposiciones eran de imposible aplicación por dos motivos: por un lado, el decreto sólo reconocía a las piezas bolivianas de 900 milésimos de fino (esto es, solo aquellas acuñadas entre 1859-63 y las que respetaron los lineamientos de la ley de monedas de Bolivia de 1863), por lo que quedaban excluidas las monedas febles, como los "cuatros y los melgarejos"24. Por otro lado, aunque no contamos con datos oficiales, es altamente probable que los bancos estuvieran encajados y rescataran sus billetes con los cuatros febles ${ }^{25}$.

${ }^{23}$ Diario El Sol, Rosario, 13-06-1877

24“"Decreto señalando la forma a que quedan reducidos los valores asignados a las monedas de plata estrangeras por decreto del 6 de junio último" (Agote, 1881, CCCXIV). Estos valores se actualizaron mediante nuevos decretos en mayo de 1877 y en enero de 1879. Por su parte, la ley 835 (Reorganización del Banco Nacional), sancionada el 24 de octubre de 1876 establecía en su artículo 22 que los bancos de emisión debían cambiar todos sus billetes a pesos fuertes en el término de un año. Esta disposición, como es bien sabido, no se cumplió ante la imposibilidad del Estado Nacional de establecer una moneda metálica de base para las operaciones. Ver República Argentina (1890, pp. 50-54).

${ }^{25}$ No es común encontrar en las fuentes referencias específicas sobre el tipo de moneda boliviana que componía los encajes metálicos, figurando solamente la denominación genérica "peso boliviano". En opinión del Diario El Sol, si los bancos del interior hubieran emitido a fuertes, sus billetes serían inconvertibles hasta el día en que se pudiera cambiar "su encaje de cuatros bolivianos por las monedas de

RHAA v. 56 n.1, 2021. ISSN: 0556-5960, ISSNe 2314-1549. CC BY-NC-SA 4.0 
Al fracaso de las iniciativas nacionales por eliminar la moneda boliviana, que en ese entonces ya incluía un abanico diversificado de piezas de distintas calidades, se sumaron las diferentes respuestas de las provincias a la coyuntura crítica de 1876, que no hicieron más que incrementar su circulación, por ser éste el único metálico amonedado disponible. La estrategia que eligieron los santafesinos para paliar los efectos de la crisis fue una de las más discutidas. El abandono de la convertibilidad en Buenos Aires en mayo de 1876, desencadenó también importantes corridas contra los bancos en el interior (Cortés Conde, 1989; Gerchunoff, Rossi y Rocchi, 2008). En la plaza santafesina el que se llevó la peor parte fue el Banco Provincial, que a sólo dos años de su instalación debió declarar el curso forzoso de sus billetes en el mes de junio de ese año (Agote, 1881, p. 436). El escenario se complicó aún más a raíz de un conflicto que enfrentó al gobierno provincial con el Banco de Londres y Río de la Plata, al que acusaron de alentar la corrida contra los billetes del BPSF. Como resultado de este enfrentamiento, que tuvo una escalada inusitada e incluyó reclamos diplomáticos de Gran Bretaña, el Banco Provincial pasó a ser el principal agente bancario de la provincia, y reforzó aún más el monopolio de la emisión que le había sido asignado el año anterior ${ }^{26}$. Esta medida, a contramano de lo que buscaba la Ley de Monedas de 1875, terminó por impulsar la circulación de pesos bolivianos, ya que el Banco tuvo una activa política de emisión de billetes nominados a esta unidad de cuenta.

Como puede observarse en el gráfico $n^{\circ} 3$, el peso boliviano monopolizó las operaciones del BPSF de manera creciente. Las emisiones en pesos fuertes prácticamente desaparecieron a partir de 1878, quedando exclusivamente billetes nominados en esta moneda. El stock de existencias de metálico en caja, en ambas nominaciones, también tendió a reducirse en relación a la masa de billetes emitidos, estrategia que generó opiniones encontradas. Los que defendían la expansión de las emisiones, sobre todo en momentos

ley". Diario El Sol, Rosario, 13-06-1877. En similar sentido se expresaba Hansen sobre la situación en 1878, quien además de hacer referencia a "emisiones vergonzantes de pequeños bancos locales en algunas provincias", también afirmaba que la circulación de metálico se componía "casi exclusivamente de cuatros bolivianos". (Hansen, 1895, p. 244). Por su parte, Pillado señala que además de los cuatros, también corrían mayormente los melgarejos, pese a que ambos habían sido prohibidos por los decretos de junio y septiembre de 1876 (Pillado, 1901: 48).

${ }^{26}$ Este episodio ha sido objeto de destacadas investigaciones. Ver al respecto, estudios específicos Gallo (2006); Damianovich (1977). Otros análisis más generales en Ferns (1968); Joslin (1963).

RHAA v.56 n.1, 2021. ISSN: 0556-5960, ISSNe 2314-1549. CC BY-NC-SA 4.0 
críticos de la economía provincial (como en 1878 o 1880), destacaban que era la única herramienta disponible para hacer frente a la escasez de crédito. Por el contrario, los opositores a la política de emisión sin respaldo en metálico reclamaban los perjuicios que el creciente premio de esos billetes sobre el oro generaba en las transacciones comerciales. Además, se criticaba la emisión en tanto se la relacionaba con la necesidad del Estado provincial por cubrir el déficit creciente del gasto público.

Gráfico $n^{\circ}$ 3: Evolución de las existencias en metálico y de la emisión monetaria del BPSF entre 1876 y 1883

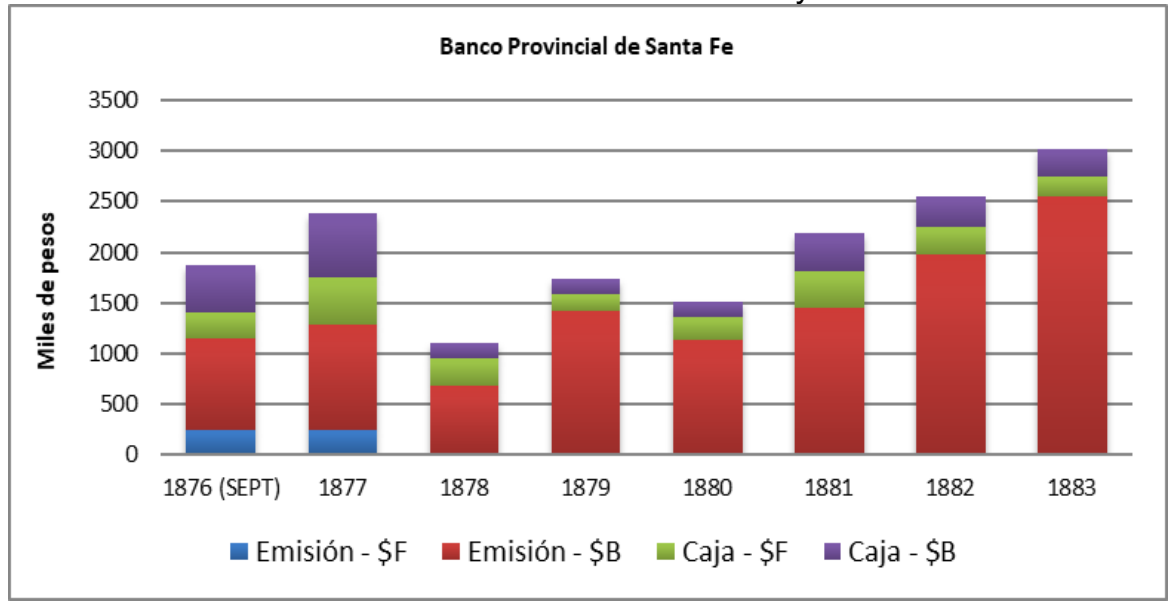

Fuente: Elaboración propia a partir de datos tomados de Agote (Tomo II, 1884, p. 276). Nota: (\$F) pesos fuertes; (\$B) pesos bolivianos.

Más allá de los inconvenientes que traía aparejados el exceso de emisión por parte del BPSF, el problema del circulante boliviano pasó a ocupar un lugar preponderante para las autoridades del gobierno central, luego de la definitiva unificación política, en 1880. La ley nacional de unificación monetaria de 1881 fue un primer paso en ese sentido, aunque no tuvo efectos inmediatos. Además de obligar a los bancos de emisión a imprimir billetes pagaderos en moneda nacional, otorgaba al Banco Nacional un plazo de dos años para renovar sus emisiones a moneda nacional $y$, al mismo, tiempo quedaba expresamente prohibida la emisión de nuevos billetes luego de 30 días de sancionada la ley (Agote, 1881, CCCXXV). Sin embargo, su aplicación se demoraría, sobre todo porque el retiro de la plata boliviana en circulación implicó una larga negociación con las provincias 
para determinar las formas de rescate y su precio. Además, como puede notarse, y a contramano de la ley, el BPSF continuó incrementando sus emisiones en moneda boliviana con el objetivo de atender la necesidad de moneda en una economía que atravesaba un franco periodo de crecimiento.

Finalmente, se determinó que la Casa de Moneda absorbería hasta 2 millones de pesos bolivianos a un valor de 0,72 pesos nacionales oro, es decir, de la nueva moneda. El proceso culminó en abril de 1883 con el retiro de 1.999.216 pesos bolivianos de circulación, y según se desprende de la prensa rosarina, los efectos en la plaza local se sintieron rápidamente ${ }^{27}$. El Diario La Capital, en su reporte del mercado del mes de mayo, afirmaba que debido al canje y a que el BPSF había logrado un préstamo de un millón de libras esterlinas para reforzar sus encajes en oro, ya nadie operaba en moneda boliviana: "Se ve pues que de suyo la desmonetización del boliviano es un hecho consumado..."28. No obstante, los billetes santafesinos continuaron circulando hasta fines de octubre de ese año, cuando finalmente fueron rescatados por el banco a un valor de 0,64 pesos moneda nacional.

Finalizaba así la era de la circulación de moneda boliviana (metálica y fiduciaria) en la economía santafesina. El surgimiento de la nueva moneda nacional como el único circulante autorizado por ley en todo el territorio coincidió con el boom económico que experimentó la economía santafesina a partir del afianzamiento del proceso de colonización agrícola, aunque, claramente, no puede desconocerse que las bases de dicha expansión se sentaron en las tres décadas anteriores. Hasta aquí hemos esbozado un panorama descriptivo de las dificultades derivadas del abanico de acuñaciones que abarcaba la moneda boliviana, y de sus derivados fiduciarios. A continuación presentaremos evidencia cuantitativa referida a la evolución de la cotización de esta moneda y su impacto sobre el crédito.

\footnotetext{
${ }^{27}$ Es de destacar que si bien la nueva moneda nacional se extendió efectivamente sobre las economías provinciales, los pesos bolivianos continuaron circulando con fuerza en las provincias del norte argentino incluso luego de 1885. Al respecto, ver: Sánchez Román (2005); Moyano (2016). Por otra parte, según se desprende de los datos de Agote (1884, p. 366), esa plata boliviana rescatada por el gobierno nacional correspondía a cuatros febles.

${ }^{28}$ La Capital, Rosario, 01-06-1883.
}

RHAA v.56 n.1, 2021. ISSN: 0556-5960, ISSNe 2314-1549. CC BY-NC-SA 4.0 


\section{Un análisis cuantitativo: el valor de la moneda y su impacto sobre el crédito}

Uno de los aspectos menos atendidos en relación al medio circulante basado en pesos bolivianos fue, sin duda, el nivel de variación de su cotización. Más allá de los datos dispersos con que contamos (Ensinck, 1970), en buena parte tomados de las cotizaciones oficiales (que, por lo demás, es difícil saber qué tipo de acuñación incluía), no disponemos de evidencia seriada que permita dar cuenta de su valor a lo largo del tiempo, tanto en moneda metálica como en su variante fiduciaria.

El gráfico $n^{\circ} 4$ busca echar luz sobre este interrogante, a partir de tres series temporales de cotización de los pesos bolivianos con respecto a la onza de oro: la primera, que mide la evolución de la moneda metálica; la segunda, que dimensiona la marcha de los billetes nominados en $\$ B$ del BPSF y, por último, la de la cotización de la onza de plata sobre la de oro en el mercado londinense.

Gráfico $n^{\circ}$ 4: Cotizaciones de la plata amonedada y en billetes en Santa $\mathrm{Fe}$ y de la onza de plata en Londres

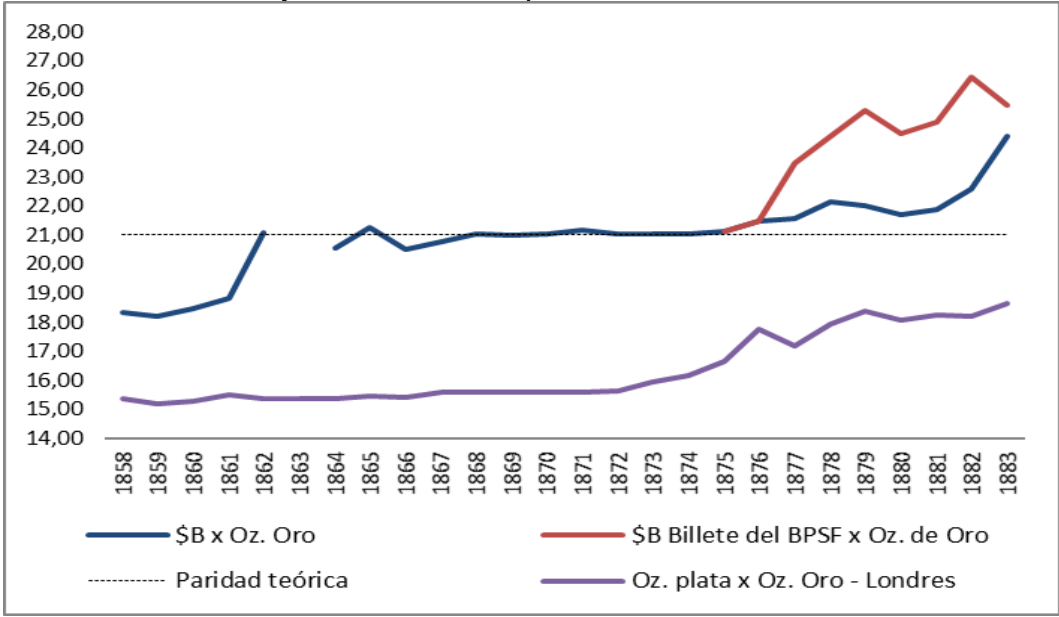

Fuente: Elaboración propia a partir de los documentos detallados en el apartado "Fuentes y Metodología" y datos sobre precio internacional de la plata tomados de www.measuringworth.com (Gold/Silver Price Ratio - London Market). Nota: (\$F) pesos fuertes; (\$B) pesos bolivianos; (Oz) onza. 
De las tendencias observadas, se desprenden al menos tres cuestiones centrales sobre su dinámica en la economía santafesina. La primera es que la plata boliviana que corría en Santa Fe hasta 1861 no parecía estar monopolizada por las piezas febles, a juzgar por su baja cotización. El hecho de que la plata amonedada boliviana en Santa Fe haya cotizado en el orden de los 18/19 pesos por onza de oro en esos años estaría indicando la presencia de piezas fuertes o bien con alguna fracción de moneda feble. La paridad teórica de las piezas adulteradas (al menos las de 8 dineros y 667 milésimos de fino) era de 21 pesos por onza de oro, por lo que esta baja cotización podría tener dos explicaciones: o bien las piezas febles bolivianas aún no habían sido completamente diferenciadas de las fuertes en el mercado, o la circulación de cuatros todavía no había llegado a gran escala a la plaza santafesina a inicios de 1860. Por lo demás, en 1862 se suscitó un punto de inflexión, ya que la cotización sufrió una brusca suba, de más de 10\%, para estacionarse así en el valor real de la plata de 667 milésimos, que era de 21 pesos por onza. En principio, podría deberse al complicado panorama internacional, derivado de la Guerra de Secesión en los Estados Unidos, aunque en los mercados de Londres el precio de la plata no tuvo mayores alteraciones. Sí es preciso destacar que, justamente en el mismo período, el circulante fiduciario de Buenos Aires tuvo un comportamiento alcista similar ${ }^{29}$. Es probable que esa suba se haya debido, más que por el aumento de piezas febles en la plaza santafesina, por un problema de stock de oro, que no sólo habría afectado al comercio local, sino también al nacional ${ }^{30}$.

La segunda cuestión destacable reside en que la cotización de la moneda boliviana entre 1864 y la crisis de 1876 tuvo una amplia convergencia con la tendencia experimentada por la de Buenos Aires, que entre 1867 y 1876 mantuvo un tipo de cambio fijo. Más allá de la breve oscilación en 1865 y 1866, la paridad en torno a 21 pesos por onza se mantuvo estable en todo ese período. Sin dudas, el circulante metálico estuvo ya determinado por las

\footnotetext{
${ }^{29}$ Series de cotización de pesos moneda corriente de Buenos Aires en Alvarez (1929, p. 100 y 113).

${ }^{30} \mathrm{Al}$ respecto, es importante resaltar que en febrero de 1861 Uruguay prohibiría la circulación de la moneda feble boliviana, por no cumplir su ley monetaria. Según el decreto respectivo, las piezas de medio y un cuarto patacón boliviano se introducían "en gran cantidad por el litoral de la República". En similar sentido actuó el sector mercantil en los dos puertos principales del sur de Brasil, rebajando un $37,5 \%$ el valor de los cuatros bolivianos con respecto al patacón fuerte, "por ser de plata mala" (traducción del autor). Diario Correio Mercantil, Rio de Janeiro, 09-10-1862.
}

RHAA v.56 n.1, 2021. ISSN: 0556-5960, ISSNe 2314-1549. CC BY-NC-SA 4.0 
piezas febles; es decir, que las nuevas piezas decimales de 500 granos ponderales derivadas de la ley de monedas de Bolivia de 1863 en principio no llevaron a la baja a la cotización.

El tercer punto a remarcar es que la crisis de 1876 abrió un nuevo panorama, marcado por grandes cambios, que se cerraría recién a finales de 1883. El primero de estos tuvo que ver con la progresiva desvalorización de la plata en el mercado internacional, que afectó en buena medida al circulante local. El segundo, y más importante, fue la expansión de la política de emisión del BPSF. Al haber conseguido el monopolio de la emisión, sus billetes pasaron a dominar el circulante de base boliviana. Debido a sus altos niveles de emisión -no siempre respaldados por base metálica-, estos billetes estuvieron sujetos a un quebranto creciente que, sin embargo, también se observó en el metálico. En particular desde 1881, justamente en los inicios de la unificación monetaria, las piezas de plata amonedada boliviana tuvieron una depreciación constante hasta su definitiva desmonetización, en mayo de 1883.

En síntesis, la evolución de la cotización de estas monedas pareció seguir tres grandes momentos: el primero, hasta 1862, en el cual la cotización estuvo por encima del valor teórico de las piezas febles. El segundo, en el que el numerario boliviano alcanzó su paridad (1864) y mantuvo una relativa estabilidad al calor de la convertibilidad de Buenos Aires. El tercero, caracterizado por el lento proceso de desmonetización de este circulante en Santa Fe, que se inició con la fracasada ley de monedas de 1875 y culminó con el definitivo rescate de metálico y billetes en 1883. Este último período fue el más convulsionado, tanto por los vaivenes que atravesaba la plata en el mercado internacional, como por las dificultades que debió enfrentar la provincia por estar encajada en esta moneda y tener su emisión fiduciaria nominada en ésta.

Ahora bien, el último interrogante que buscaremos responder en este artículo es el del comportamiento del crédito en la provincia, habida cuenta de los vaivenes sufridos por las características de su base monetaria. Es sabido que al sentarse las bases políticas y económicas post Batalla de Caseros, la necesidad de expansión de fronteras y de mano de obra y capital para poner en marcha la economía agraria, requería la formación de un sistema financiero que organizara el ahorro privado y dinamizara los préstamos en dinero. 
Como hemos visto, el auge de Rosario como enclave mercantil del Interior operó como un factor fundamental para la transformación del sistema de crédito a través de la instalación de los primeros bancos de emisión, que también realizaban operaciones de descuento y de depósitos a la vista o a plazo. La emergencia de los bancos vino a transformar la operatoria de las casas mercantiles tradicionales, que trabajaban con tasas de descuento a muy corto plazo y con niveles elevados debido al riesgo implícito. A partir de entonces, la oferta de crédito se fue concentrando en esos bancos más sólidos, respaldados por un fuerte capital, y que pronto constituyeron carteras de depósitos de consideración. Los comerciantes continuaron su rol financiero, pero ahora en gran medida como intermediarios entre esos bancos y los productores y tomadores de menor dimensión, además de concentrarse en el crédito hipotecario (Djenderedjian y Martirén, 2018).

Sin embargo, estas transformaciones no tuvieron efectos inmediatos en toda la economía provincial; el acceso al crédito en las plazas que aún no contaban con sucursales bancarias (en particular las de las florecientes colonias agrícolas que estaban surgiendo en la campaña santafesina) se hizo por vía notariada y sobre la base de garantías hipotecarias. La falta de financiación en una economía en pleno crecimiento, que además tenía un gran potencial al ofrecer respaldo hipotecario, fue un problema que generó constantes observaciones por parte de los funcionarios provinciales, en particular los que informaban sobre el estado de las colonias agrícolas. Guillermo Wilcken, por ejemplo, en su informe de 1872 afirmaba al respecto:

(...) De los datos adquiridos, se deduce que, estos grandes establecimientos bancarios en Santa Fe solo sirven para facilitar al hombre rico y de buenas garantías, los medios y recursos de explotar con ellos al industrial, al artesano, al agricultor, entidades de nuestra sociedad que no tienen crédito alguno en los Bancos particulares.

Cualquier colono representa en tierras, animales, implementos de agricultura, etc, un capital de 5 a 15.000 pesos bolivianos, y sin embargo no gozan de crédito en los bancos ni aún por 100 pesos!

Pero ciertos usureros de fortuna, toman de los bancos particulares grandes sumas de dinero a módico interés, y especulan con él, dándolo en pequeñas cantidades a fuerte interés de 2 y 2,5 por ciento mensual a los colonos (Wilcken, 1873, p. 276) 
Es altamente probable que el funcionario exagerara en relación a la tasa de interés corriente, y que en su informe buscara presionar para bajar el costo del financiamiento local. Sin embargo, lo interesante es que la la cita pone en evidencia la necesidad de que los bancos abrieran secciones hipotecarias durante la década de 1870. Para entonces, las colonias agrícolas ya habían dejado de ser un experimento riesgoso para tornarse un negocio con gran potencial (Gallo, 1983; Djenderedjian, Bearzotti y Martirén, 2010; Martirén, 2016). Su principal base de acumulación eran los activos inmobiliarios, aunque el alcance de los bancos en la campaña era reducido, o dependía de canales indirectos de intermediación. En este contexto, el aumento del precio de la tierra operaba como una variable clave para la oferta de dinero a crédito. Existían de este modo prestamistas particulares (esto es, personas físicas, entre los cuales se encontraban comerciantes, propietarios de bienes raíces, que manejaban carteras de créditos, escribanos, entre otros) o bien firmas comerciales que conformaban una suerte de redes de crédito notariado, diseminadas entre los productores de la campaña o en el mercado urbano extrabancario. También se ofrecía dinero a crédito derivado de rentas particulares 0 ahorros y excedentes transitorios o permanentes, producto de herencias recibidas. Este tipo de préstamos fueron los que alimentaron la financiación privada en todo el interior provincial, aunque también tuvieron un peso importante en las plazas urbanas (Martirén, 2016, p. 58). Se trata, sin dudas, de un factor a tener en cuenta si se considera que en la provincia de Buenos Aires el mayor volumen de dinero circulante y su canalización hacia el mercado crediticio rural ayudó también a financiar en ese momento la expansión del lanar y a alimentar el mercado de tierras.

En suma, la oferta de crédito tenía en general tres tipos de modalidades: 1) la de descuento de documentos por parte de prestamistas de corto plazo o bien adelantos en cuenta corriente por parte de casas comerciale; 2) el bancario, que vino a cubrir los préstamos a corto y largo plazo, pero también ofreció distintas modalidades de captación del ahorro privado; 3) el notariado o extrabancario, que incluía transacciones entre particulares rubricadas por escribano público, con garantía hipotecaria.

El gráfico $n^{\circ} 5$ expone la evolución nominal de las tasas de interés corriente en los tres tipos de formas crediticias. La tasa de descuentos en plaza, si bien es de índole general (se toma del dato promediado genérico que ofrecían los diarios en los apartados sobre mercados de cambios), presenta un panorama sugerente sobre el funcionamiento del nivel de descuentos en la plaza mercantil de Rosario hasta 1870. Los guarismos de la década de

RHAA v. 56 n.1, 2021. ISSN: 0556-5960, ISSNe 2314-1549. CC BY-NC-SA 4.0 
1850, que llegaban al 2,5 o 2,75\% mensual estarían dando cuenta de la falta de estructuras crediticias en una plaza que comenzaba a posicionarse como estratégica en el comercio nacional. Coincide asimismo con la baja cotización que tenía el peso boliviano en esos años (como se vio en el gráfico anterior, la plata boliviana cotizaba en torno a los 18 pesos por onza), lo que indicaría, tal vez, que la oferta de circulante era limitada en relación al oro, o bien, que ese tipo de moneda contaba aún con baja demanda. Para mediados de los años 1860, esta tasa tendió a converger con las bancarias y las de crédito notariado. Seguramente la llegada de los bancos de emisión a mediados de la década de 1860 haya transformado la estructura crediticia e impactado positivamente en una disminución del costo del dinero.

Gráfico n5: Evolución de las tasas de interés corriente en la estructura de crédito santafesina (1858-1883)

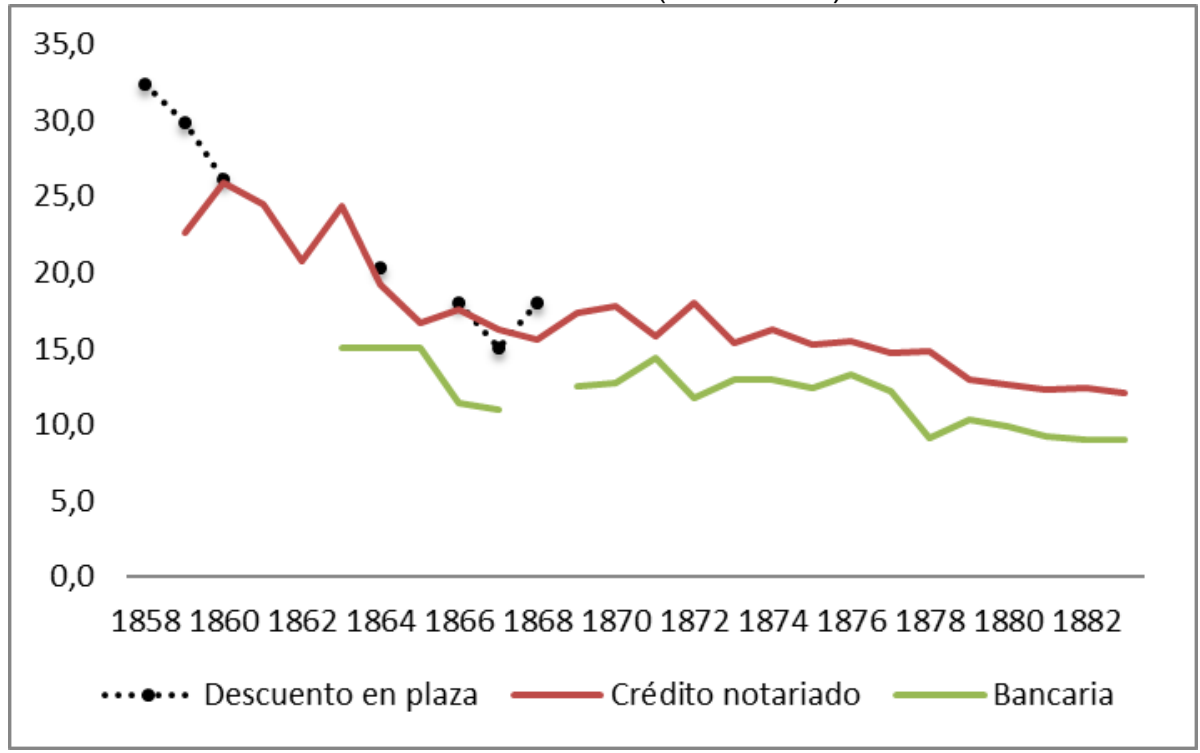

Fuente: Elaboración propia a partir de datos del mercado de cambios y de crédito publicados en diarios rosarinos y de operaciones a crédito entre particulares rubricadas por escribanos públicos. Las fuentes fueron descriptas en el apartado "Fuentes y metodología". 
Es importante mencionar que cuando los bancos iniciaron su giro y las tasas comenzaron una tendencia descendente, el boliviano alcanzó su paridad teórica de 21 pesos por onza. La dinámica de captación de fondos por parte de los bancos y la circulación fiduciaria debieron haber incrementado la liquidez del sistema e aumentando el volumen de fondos dirigido al mercado de crédito. Por lo demás, si bien se identifican algunas coyunturas críticas hasta 1883, la tendencia de las series no parece haber sufrido el nivel de oscilaciones que caracterizó a la cotización de la moneda. Es decir, a pesar de los problemas inherentes a la moneda boliviana y a su derivado fiduciario, la tasa de interés tuvo un comportamiento a la baja, en línea con el mercado nacional ${ }^{31}$.

\section{Conclusiones}

Moneda y crédito son dos tópicos que necesitan estudiarse con mayor detenimiento en algunas económicas decimonónicas del interior del país. La historiografía ha abordado con mucho mayor nivel de detalle ambos temas para el caso de Buenos Aires, aunque la escasez de fuentes y los problemas derivados de la falta de una moneda nacional han dificultado las investigaciones en las provincias. Aspectos clave para entender el funcionamiento de estas economías, como la cotización nominal de la moneda boliviana o la evolución de las tasas de descuento o interés bancario, presentan aún importantes lagunas.

El artículo pretendió avanzar sobre estos aspectos a partir del análisis del caso de Santa Fe, una de las economías provinciales de mayor crecimiento durante la segunda mitad del siglo XIX. En la primera parte, realizamos un repaso sobre las características del circulante y sus complicaciones derivadas. Vimos así que las piezas acuñadas luego de la independencia boliviana comenzaron a llegar a los mercados del interior en dos modalidades, la fuerte (en teoría, con un contenido de fino de 902 milésimos y 542 granos de peso) ${ }^{32}$ y la feble, que se tornó una denominación genérica y pasó a englobar a las distintas acuñaciones adulteradas que se habían

\footnotetext{
${ }^{31}$ Series de tasas de interés en Buenos Aires para el período en Cortés Conde y McCandless (2001, p. 399).

${ }^{32}$ Es necesario ser prudentes a la hora de identificar el peso ponderal de la plata 'fuerte', ya que bajo esta denominación se incluía una serie de diversas acuñaciones, tanto del período colonial ('macuquina', 'pesos españoles de rostro'), como independiente ('pesos patrios'), que tenían diferencias (aunque mínimas) en su cotización con respecto al oro.
}

RHAA v. 56 n.1, 2021. ISSN: 0556-5960, ISSNe 2314-1549. CC BY-NC-SA 4.0 
realizado en Bolivia desde 1830.

De aquí se desprenden tres cuestiones importantes: la primera, es que el problema con esta moneda no era tanto su carácter extranjero, sino la disímil calidad que tenían las distintas partidas, algunas con 667 milésimos, otras 900 (pero con menor peso ponderal) e incluso las más rechazadas, que ni siquiera llegaban a cumplir con la ley de 8 dineros. Si bien es difícil estimar qué cantidades de estas piezas ocuparon el circulante santafesino, es razonable pensar que fueron los famosos cuatros o moneda de cuatro reales (medio peso) y 8 dineros (667 milésimos de fino) acuñada en Bolivia desde el decreto de Santa Cruz en 1829 hasta 1859. Es probable también que los melgarejos, famosos por su mala calidad y acuñados a mediados de la década de 1860, también hayan tenido gran circulación, a juzgar por los testimonios de la época. La segunda, es que la unidad de cuenta denominada 'peso boliviano' no significó un medio circulante homogéneo o que pueda resumirse con la generalización de 'moneda feble'. Las diferentes calidades generaron trastornos en las economías provinciales, ya que al tener alterado su valor según su cuño, estaban sujetas a numerosas oscilaciones y premios. Este es un tema de crucial importancia para entender las dificultades que debió atravesar del sistema monetario nacional logrado en los primeros años de 1880. La tercera cuestión, no menos importante, está asociada al peso que los mercados de exportación de países limítrofes (en particular, Bolivia) tuvieron sobre el crecimiento económico del interior argentino entre mediados de siglo y la definitiva implantación de la moneda nacional. El circulante monetario derivado del intercambio comercial fue sin dudas uno de los grandes responsables del funcionamiento económico (y financiero) en las provincias del interior, sobre todo con la emergencia de Rosario como articulador de esos mercados. Reforzó todavía más, asimismo, la supervivencia de lazos económicos que parecían haberse desdibujado con la crisis del imperio español y la atlantización de la economía rioplatense.

Por lo demás, desde el plano cuantitativo buscamos mostrar que el establecimiento de las primeras instituciones bancarias en la década de 1860 , más que evitar esta moneda, reforzó aún más su rol en el circulante. Se trató de una derivación lógica, ya que estos bancos de emisión sólo podían cubrir sus encajes con el único metal disponible en plaza, que era el peso boliviano. Así, desde que fueron autorizados en 1866 a emitir moneda en papel nominada en circulante extranjero, estas instituciones lograron imponer en el mercado sus billetes, algo en lo que la Confederación había fracasado una década antes con papeles emitidos sobre pesos fuertes.

RHAA v.56 n.1, 2021. ISSN: 0556-5960, ISSNe 2314-1549. CC BY-NC-SA 4.0 
La presencia de la moneda boliviana en el comercio del interior, y al mismo tiempo las dificultades del Estado nacional para establecer su propia moneda, cobraron gran visibilidad en la década de 1870. Este convulsionado decenio pondría de manifiesto al menos tres graves problemas asociados a este numerario: la ya apuntada existencia de distintas calidades de metal amonedado; la creciente emisión de billetes sin respaldo por parte del BPSF, que desde 1875 logró el monopolio de la emisión; y las grandes dificultades económico-financieras para sentar las bases de funcionamiento de un mercado nacional de bienes y moneda. La crisis de 1876 terminó poniendo de manifiesto las limitadas estrategias provinciales por munirse de circulante.

No obstante, pese a todos los inconvenientes emanados de la circulación del boliviano, la provincia logró asentar en la década de 1870 las bases de su economía agrícola, que generaría importantes excedentes en las postrimerías del siglo. Es decir, estas piezas ofrecieron el acceso a encajes metálicos que (aunque con varias oscilaciones) operaron como reserva de valor de un circulante que se multiplicaba por medio del nuevo dinero bancario. La consiguiente remonetización de esos encajes a través de billetes, realizada por los bancos de emisión desde 1866 permitió la expansión de un nuevo circulante, que dinamizó a la economía provincial. A diferencia de otras experiencias con diferentes anclajes (el de los vales de Aduanas para los billetes del Banco Nacional; o en plata fuerte para las emisiones del Banco Mauá), que no funcionaron por no contar con suficiente liquidez (al menos en el caso santafesino), el circulante convertible a boliviano se volvió una herramienta muy útil para la generación de dinero y la expansión de las actividades comerciales y el crédito.

El soporte cuantitativo nos lleva a pensar en esa dirección, al menos al considerar la expansión de diferentes modalidades de crédito y la tendencia decreciente de la tasa durante todo el período. El volumen total del crédito, limitado hasta la aparición de los bancos por las tasas elevadas y los muy cortos plazos, comenzó a expandirse gracias a la emergencia del crédito bancario y de otro sistema de préstamos (no bancario) de base hipotecaria. En otros términos, el mayor nivel de circulante promovido por los bancos y la formación una estructura de crédito basada en la garantía hipotecaria presionaron a la baja la tasa de interés, y disminuyeron sin duda el nivel riesgo implícito característico de la etapa pre-bancaria. 
En suma, si bien se trata de apuntes preliminares sobre un tema que debe ser reforzado con mayor evidencia empírica, es de destacar que con todos sus problemas, la moneda boliviana ocupó un lugar central entre los factores que explican el exitoso ciclo económico santafesino de la segunda mitad del siglo XIX.

\section{Anexo ${ }^{\circ} 1$ : Cantidad y calidad de la plata amonedada en Bolivia entre} 1830 y 1862

\begin{tabular}{l|c|c|c}
\multicolumn{1}{c}{ Año } & Fuerte & Feble & $\begin{array}{c}\text { Peso de 400 granos } \\
\text { (ley de monedas de } \\
\text { 1859) }\end{array}$ \\
\hline 1830 & 1.583 .083 & 206.218 & \\
1831 & 1.678 .750 & 211.242 & \\
1832 & 1.555 .050 & 306.910 & \\
1833 & 1.640 .356 & 313.382 & \\
1834 & 1.652 .400 & 309.400 & \\
1835 & 1.471 .070 & 509.091 & \\
1836 & 1.664 .130 & 303.187 & \\
1837 & 1.768 .510 & 301.563 & \\
1838 & 1.565 .496 & 492.006 & \\
1839 & 1.887 .850 & 466.905 & \\
1840 & 2.086 .172 & 514.335 & \\
1841 & 1.396 .550 & 917.456 & \\
1842 & 1.255 .705 & 1.166 .532 & \\
1843 & 1.126 .429 & 1.001 .963 & \\
1844 & 921.205 & 1.094 .341 & \\
1845 & 1.620 .517 & 299.396 & \\
1846 & 1.043 .843 & 863.744 & \\
1847 & 586.271 & 1.316 .599 & \\
1848 & 504.210 & 1.055 .089 & \\
1849 & 671.075 & 947.270 & \\
& & &
\end{tabular}




\begin{tabular}{|c|c|c|c|}
\hline 1850 & 771.672 & 1.284 .225 & \\
\hline 1851 & 885.092 & 1.416.192 & \\
\hline 1852 & 499.852 & 1.990 .061 & \\
\hline 1853 & 95.930 & 2.594 .599 & \\
\hline 1854 & 49.385 & 2.396 .600 & \\
\hline 1855 & 63.401 & 2.345 .246 & \\
\hline 1856 & 26.944 & 2.634 .078 & \\
\hline 1857 & 3.458 & 2.634 .550 & \\
\hline 1858 & 23.548 & 2.378 .744 & \\
\hline 1859 & 68.701 & 1.575 .920 & 774.711 \\
\hline 1860 & & & 2.359.547 \\
\hline 1861 & & & 2.113 .642 \\
\hline 1862 & & & 2.272 .340 \\
\hline 1863 & 2.326 .153 & & \\
\hline 1864 & 1.899 .914 & & \\
\hline 1865 & 1.469 .589 & 239.930 & \\
\hline 1866 & 884.359 & 1.158 .716 & \\
\hline 1867 & 1.704 .102 & 488.660 & \\
\hline 1868 & 772.310 & 1.887 .421 & \\
\hline 1869 & 26.004 & 1.652 .907 & \\
\hline 1870 & 766.629 & 396.206 & \\
\hline 1871 & 1.734 .411 & & \\
\hline IOTAL & 41.750 .119 & 39.670 .680 & 7.520 .241 \\
\hline
\end{tabular}

Fuente: Los datos desde 1830 hasta 1862 fueron tomados de Vargas (1862: p. 25). Los correspondientes al período 1863-1871, de Prado (2001, p. 180). 


\section{Bibliografía}

Agote, P. (1881). Informe del Presidente del Crédito Público Nacional sobre la Deuda Pública, Bancos y emisiones de papel moneda y acuñación de moneda. Imp. La Tribuna Nacional.

Agote, P. (1884). Informe del Presidente del Crédito Público Nacional sobre la Deuda Pública, Bancos y acuñación de Moneda. Tomo II. Imp. La Universidad de J.N. Klingelfuss.

Albaizeta, M. E. (1987). Notas acerca de las inversiones bancarias en la provincia de Santa Fe. Anuario de la Escuela de Historia, (12), pp. 253-70.

Alvarez, J. (1929), Temas de Historia Económica Argentina. El Ateneo.

Amaral, S. (1988). El descubrimiento de la financiación inflacionaria. Buenos Aires, 1790- 1830. Investigaciones y ensayos, (37), pp. 379-418.

Beck, Ch. (1865). La Republique Argentine. Delafontaine et Rouge.

Benavídes, J. (1972). Historia de la moneda en Bolivia. Ed. Puerta del Sol.

Bonaudo, M. (2006). La organización productiva y política del territorio provincial (1853-1912). En D. Barriera (Dir.), Nueva historia de Santa $\mathrm{Fe}$, Tomo VI (pp-103-126). Prohistoria Ediciones.

Bonaudo, M. y Sonzogni, E. (1997). El problema de la fiscalidad en la reorganización provincial en la etapa posrosista. Santa Fe (18531880). Prohistoria (1), pp. 73-90.

Bragoni, B. (2005). Mercados, monedas y crédito a la luz del funcionamiento de una entidad bancaria (Mendoza, 1866-1879). Desarrollo Económico, 45 (177), pp. 55-74.

Comisso, A. (2012). El Banco Provincial de Santa Fe, 1874-1880. En C. Frid y N. Lanciotti. De la expansión agraria al desarrollo industrial, la economía de Santa Fe entre 1850 y 1970 (pp. 49-86). Prohistoria,

Conti, V. (2003). Circuitos mercantiles, medios de pago y estrategias en Salta y Jujuy (1820-1852). En A. Irigoin y R. Schmit (2003). La desintegración de la economía colonial. Comercio y moneda en el interior del espacio colonial (1800-1860) (pp. 113-133) Biblos.

Converso, F. (2004). Las cuestiones monetarias y los costos del crédito. Córdoba, 1850-1900. Cuadernos de Historia. Serie Economía y Sociedad, (6), pp. 101-147. 
Cortés Conde, R. (1989) Dinero, deuda y crisis. Evolución fiscal y monetaria de la Argentina, 1862-1890. Sudamericana / Instituto Di Tella.

Cortés Conde, R. y Mc Candless, R. (2001). Argentina: From Colony to Nation: Fiscal and Monetary Experience of the Eighteenth and nineteenth centuries, en R. Cortés Conde y M. Bordo. Transferring Wealth and Power from the Old to the New World. Monetary and Fiscal Institutions in the 17th trhough the 19th Centuries (pp. 378-413). Cambridge University Press.

Dalla Corte, G. (2009). Lealtades firmes. Redes de sociabilidad y empresas: La "Carlos Casado SA" entre la Argentina y el Chaco Paraguayo (1860-1940). Consejo Superior de Investigaciones Científicas.

Damianovich, A. (1977). El proteccionismo financiero de Servando Bayo. En Academia Nacional de la Historia. Tercer Congreso de Historia Argentina y Regional, Tomo I, pp. 149-160.

De los Ríos, E. (2017). Gobernar es poblar. Política fiscal, recaudación impositiva y cultura tributaria. Santa Fe (Argentina, 1855-1873). Prohistoria.

Djenderedjian, J, Bearzotti, S. y Martirén, J. (2010), Historia del Capitalismo Agrario Pampeano. Expansión agrícola y colonización en la segunda mitad del siglo XIX, 2 tomos. Teseo.

Djenderedjian, J, y Martirén, J. (2018). Medio circulante, fragmentación política y financiación fiscal: los problemas de la construcción de un área monetaria única en la Argentina del siglo XIX. Ponencia presentada en Jornada Internacional Crédito, finanzas y deuda en el mundo hispano americano. Experiencias peninsulares y rioplatenses, siglos XVII-XIX, Instituto Ravignani, Buenos Aires, abril.

Ensinck, O. (1970). Moneda y bancos en la provincia de Santa Fe. Separata de Historia de las Instituciones de la Provincia de Santa Fe. Tomo 3, Libro IV. Imp. Oficial de la Provincia.

Fernández, S. (1999). Burguesía y empresarios. La ciudad y la región en el cambio de siglo (Rosario, 1880-1914). Tesis de Maestría en Ciencias Sociales. Flacso, Buenos Aires.

Ferns, H. S. (1968). Gran Bretaña y Argentina en el siglo XIX. Solar/ Hachette.

Frid, C. y Lanciotti, N. (coords.) (2013). De la Expansión Agraria al Desarrollo Industrial: la economía de Santa Fe entre 1870 y 1950. RHAA v. 56 n.1, 2021. ISSN: 0556-5960, ISSNe 2314-1549. CC BY-NC-SA 4.0 
Prohistoria.

Gallo, E. (1983). La Pampa Gringa. Sudamericana.

Gallo, E. (2006). El gobierno de Santa Fe vs. el Banco de Londres. En E. Gallo. Colonos en Armas (pp. 110-131). Sudamericana.

Garcilazo, R. (2015). Empresarios pampeanos entre la fortuna el poder y la pervivencia. El caso de Juan Canals, Rosario 1870-1901, Tesis de Doctorado. Universidad Nacional de Rosario, Facultad de Humanidades y Artes.

Gerchunoff, P.; Rocchi, F; Rossi, G. (2008). Desorden y progreso. Las crisis económicas argentinas, 1870-1905. Edhasa.

Hansen, E. (1895). Chile y la República Argentina. Paralelo económico. El Hogar y la Escuela.

Irigoin, M. A. (2000). Inconvertible Paper Money, Inflation and Economic Performance in Early Nineteenth Century Argentina. Journal of Latin America Studies, 32 (2), pp. 333-359. https://doi.org/10.1017/S0022216X00005769

Irigoin, M. A. (2009). Gresham on Horseback: The Monetary Roots of Spanish American Political Fragmentation in the Nineteenth Century. The Economic History Review, 62 (3), pp. 551-575. https://doi.org/10.1111/j.1468-0289.2008.00430.x

Irigoin, M. A. (2010). Las raíces monetarias de la fragmentación política de la América española en siglo XIX. Historia Mexicana, LIX (3), pp. 919979.

Irigoin, A. y Schmit, R. (2003). La desintegración de la economía colonial. Comercio y moneda en el interior del espacio colonial (1800-1860). Biblos.

Joslin, D. (1963). A Century of Banking in Latin America. Oxford University Press.

Langer, E. y Conti, B. (1991). Circuitos comerciales y cambio económico en los andres Centromeridionales (1830-1930). Desarrollo Económico, 31 (121), pp. 91-111.

Ludlow, L. y Marichal, C. (Coords.) (1998). La banca en México, 1820-1920. Instituto de Investigaciones Dr. José María Luis Mora. 
Marichal, C. y Gambi, T. (Eds.) (2017). Historia bancaria y monetaria de América Latina (siglos XIX y XX). Universidad de Cantabria.

Martirén, J. L. (2016). La transformación farmer. Colonización agrícola y crecimiento económico en la provincia de Santa Fe durante la segunda mitad del siglo XIX. Prometeo.

Míguez, E. (1985). Las Tierras de los ingleses en la Argentina (1870-1914). Editorial de Belgrano.

Mitre, A. (1986). El monedero de los Andes. Región económica y moneda boliviana en el siglo XIX. Hisbol.

Moyano, D. (2016). El tributo de la caña de azúcar...". En P. Parolo y C. Herrera, C. (Comps.). Estado, impuestos y contribuyentes. La construcción del sistema fiscal en Tucumán en el siglo XIX (pp. 133189). Prohistoria.

Moyano, D. (2019). El arribo del crédito oficial. Los primeros años del Banco Nacional en las provincias del interior (1872-1882). Comentarios preliminares. Anuario del CEEED, (XI), pp. 59-118. Recuperado de https://ojs.econ.uba.ar/index.php/CEEED/article/view/1443

Platt, T. (1986). Estado tributario y librecambio en Potosí. Hisbol.

Platt, T. (2010). El feble y el fuerte. Políticas monetarias, esferas de intercambio y crisis de confianza en Potosí (Bolivia) durante el siglo XIX. Surandino Monográfico, segunda sección del Prohal Monográfico, 1 (2), pp. 1-58.

Regalsky, A. (1999). Banca y capitalismo en la Argentina, 1850-1930. Un ensayo crítico. Ciclos, IX (18), pp. 33-54.

Regalsky, A. (2006). Modernización, expansión y crisis: una aproximación a la historiografía de las finanzas, la moneda y el crédito entre 1871 y 1930. En J. Gelman (Coord.), La historia económica argentina en la encrucijada. Balances y perspectivas (pp. 101-117). Prometeo Libros/AAHE.

Regalsky, A. (2018). Moneda, Bancos y Finanzas Públicas (1860-1899). En R. Cortés Conde y G. Della Paolera (Dirs.). Nueva Historia Económica Argentina (pp. 463-505). Edhasa.

Prado, G. (2001). Efectos económicos de la adulteración monetaria en Bolivia, 1830-1870. Revista de Análisis del Banco Central de Bolivia, 4 (2), pp. 141-185. 
Prebisch, R. (1921). Anotaciones sobre nuestro medio circulante. A propósito del libro del Dr. Norberto Piñero, cap. I-IV. Revista de Ciencias Económicas, 2 (3), pp. 190-204.

Pillado, J. (1901). El papel moneda argentino, 1810-1900. Compañía SudAmericana de Billetes de Banco.

Provincia de Santa Fe (1888 y ss.) Registro oficial de la Provincia de Santa Fe. T. I. 1815-1847 [y siguientes]. Tipografía de la Revolución [y otros].

Provincia de Santa Fe (1889) Registro oficial de la Provincia de Santa Fe. T. V. 1865-1867. Tipografía de la Revolución.

República Argentina (1890). Bancos y moneda: Recopilación de leyes y decretos, 1854 á 1890. Imp. La Tribuna Nacional.

Sánchez Román, J. (2005). La dulce crisis: estado, empresarios e industria azucarera en Tucumán, Argentina (1853-1914). Universidad de Sevilla.

Segreti, C. (1975). Moneda y política en la primera mitad del siglo XIX: contribución al estudio de la moneda argentina. Fundación Banco Comercial del Norte.

Sotomayor Valdés, R. (1874). Estudio histórico de Bolivia. Imp. Andrés Bello.

Tognetti, L. (1999/2000). La banca comercial en la segunda mitad del siglo XIX. Travesía (3-4), pp. 23-38.

Vargas, P. (1863). Reflecciones económicas sobre la moneda feble de Bolivia y la moneda actual de 400 granos de peso y lei 10 dineros 20 granos. Potosí.

Wasserman, M.L.E. (2020). Deuda, papeles y compromisos en la construcción del crédito público. La Caja Nacional de Fondos de Sud América (Buenos Aires, 1818-1821)". Revista de Historia Económica / Journal of Iberian and Latin American Economic History, pp. 1-34. https://doi.org/10.1017/S0212610920000191

Wilcken, G. (1873). Las colonias. Informe sobre el estado actual de las colonias agrícolas de la República Argentina... 1872. Sociedad Anónima. 